\title{
1 Local Shifts in Inflammatory and Resolving Lipid Mediators in Response to Tendon Overuse
}

2

3 Running title: Mediator lipidome of tendon overuse

4

5 James F. Markworth ${ }^{1,2}$, Kristoffer B. Sugg ${ }^{2,3}$, Dylan C. Sarver ${ }^{2,4}$, Krishna Rao Maddipati ${ }^{5}$, Susan V. Brooks ${ }^{1,6}$ 6

$8 \quad 2$ Department of Orthopaedic Surgery, University of Michigan, Ann Arbor, Michigan.

$9 \quad{ }^{3}$ Department of Surgery, University of Michigan, Ann Arbor, Michigan.

$10{ }^{4}$ Department of Cellular \& Molecular Physiology, Johns Hopkins University, Baltimore, Maryland

${ }^{6}$ Department of Biomedical Engineering, University of Michigan, Ann Arbor, Michigan.

14 Susan V. Brooks, $\mathrm{PhD}$

15 Christin Carter-Su Collegiate Professor of Physiology

16 Professor of Biomedical Engineering

17 Professor of Molecular \& Integrative Physiology

18 University of Michigan

$192029 \mathrm{BSRB}$

20109 Zina Pitcher P1.

21 Ann Arbor, MI 48109-2002

(734) 936-2147

23 svbrooks@umich.edu 
Abstract:

Tendon inflammation has been implicated in both adaptive connective tissue remodeling and overuseinduced tendinopathy. Lipid mediators control the initiation and resolution of inflammation, but their roles within tendon are largely unknown. Here we profiled local shifts in intratendinous lipid mediators via liquid chromatography-tandem mass spectrometry in response to synergist ablation-induced plantaris tendon overuse.

31 Sixty-four individual lipid mediators were detected in homogenates of habitually loaded plantaris tendons from 32 healthy ambulatory rats. This included many bioactive metabolites of the cyclooxygenase (COX), lipoxygenase (LOX), and epoxygenase (CYP) pathways. Synergist ablation induced a robust inflammatory response at day 3 post-surgery characterized by epitenon infiltration of polymorphonuclear leukocytes (PMNs) and macrophages $(\mathrm{M} \Phi)$, heightened expression of inflammation-related genes, and increased intratendinous concentrations of the pro-inflammatory eicosanoids thromboxane $\mathrm{B}_{2}\left(\mathrm{TXB}_{2}\right)$ and prostaglandin $\mathrm{E}_{2}\left(\mathrm{PGE}_{2}\right)$. By day 7 , $\mathrm{M} \Phi$ became the predominant myeloid cell type in tendon and there were further delayed increases in other COX metabolites including $\mathrm{PGD}_{2}, \mathrm{PGF}_{2 \alpha}$ and $\mathrm{PGI}_{2}$. Specialized pro-resolving mediators (SPMs) including protectin D1 (PD1) and resolvin D6 (RvD6), as well as related pathway markers of D-resolvins (17-HDoHE), E-resolvins (18-HEPE) and 


\section{Introduction:}

Tendons are dense bands of connective tissue responsible for transfer of force from skeletal muscle to

bone (1). Like skeletal muscle, tendons can undergo compensatory hypertrophy in response to heightened

mechanical loading (2). On the other hand, repetitive tendon overuse is a major contributor to the development

of tendinopathy, a common degenerative condition characterized by chronic pain and loss of function (3).

Inflammation occurs following either acute tendon injury (4-9) or repetitive overuse (10-17), but its role in the

etiology of tendinopathy has been a matter of debate (18). The term tendinitis was classically used to describe

symptoms of painful non-ruptured tendons, inferring key involvement of an inflammatory component (19).

However, an apparent lack of polymorphonuclear leukocytes (PMNs) within diseased tendons led to the view that

tendinopathy is rather a degenerative condition of tendinosis that is devoid of inflammation (20). Nevertheless,

recent studies employing modern antibody based immunohistochemical staining techniques demonstrate that

leukocytes, most notably macrophages $(\mathrm{M} \Phi)$, are indeed often present within diseased human tendons (21),

stimulating a resurgence of interest into the potential role of inflammation in tendon biology (22).

Lipid mediators are bioactive metabolites of dietary essential polyunsaturated fatty acids (PUFA), such as

omega-6 (n-6) arachidonic acid (AA, 20:4n-6), as well as omega-3 (n-3) eicosapentaenoic acid (EPA, 20:5n-3)

and docosahexaenoic acid (DHA, 22:6n-3) (23). A wide-range of lipid mediators can be endogenously produced

via the cyclooxygenase (COX), lipoxygenase (LOX), and epoxygenase (CYP) pathways (24). These eicosanoids

and docosanoids act as important autocrine/paracrine signaling molecules in a range of physiological processes,

most notably in mediating the inflammatory response (25). Prior studies of tendon have focused overwhelmingly

on the prostaglandins, classical eicosanoid metabolites generated via the COX-1 and -2 pathways (26). Local

concentrations of prostaglandin $\mathrm{E}_{2}\left(\mathrm{PGE}_{2}\right)$ are well known to increase in rodent models of either acute tendon injury $(27,28)$ or heightened mechanical loading $(28,29)$, as well as within peritendinous tissues of exercising

humans $(30,31)$. While PMNs (32) and MФ (33) are major classical cellular sources of PGE2, resident tendon

fibroblasts (tenocytes) can also produce and release $\mathrm{PGE}_{2}$ in response to either inflammatory cytokines (34) or 
Resolution of the acute inflammatory response, characterized by cessation of PMN influx and clearance

of infiltrating leukocytes from the site of inflammation, was originally thought to be a passive event (36). More

recently, distinct families of specialized pro-resolving mediators (SPMs) were shown to be produced during the

resolution phase (37). SPM families identified to date include the AA-derived lipoxins (e.g. LXA4) (38), EPA-

derived E-series resolvins (e.g. RvE1) (39), and DHA-derived D-series resolvins (e.g. RvD1) (40), protectins (e.g.

PD1) (41), and maresins (e.g. MaR1) (42). Collectively these autocoids act as endogenous stop signals to limit

further PMN influx (43), while simultaneously stimulating key MФ functions required for timely resolution and

tissue repair (44). The discovery of SPMs has inspired the development of novel therapeutic strategies to modulate 


\section{Methods:}

Animals: Male Sprague-Dawley rats were obtained from Charles River Laboratories and housed under specific pathogen-free conditions with ad-libitum access to food and water. Rats were used for experiments at approximately 6-months of age. All animal experiments were approved by the University of Michigan Institutional Animal Care and Use committee (IACUC) (PRO00006079).

Plantaris Tendon Overuse: Myotenectomy induced synergist ablation was used to assess the local inflammatory response to mechanical overload of the plantaris musculotendinous unit as originally described by Goldberg et al. 1967 (56). Rats were anesthetized with 2\% isoflurane and preemptive analgesia provided by subcutaneous injection of buprenorphine $(0.03 \mathrm{mg} / \mathrm{kg})$ and carprofen $(5 \mathrm{mg} / \mathrm{kg})$. The skin overlying the posterior hind-limb was shaved and scrubbed with chlorhexidine and ethyl alcohol. A midline incision was made through the overlying skin and paratenon to visualize the gastrocnemius/soleus (Achilles) tendon. A full thickness tenectomy was performed to surgically remove the entire Achilles tendon mid-substance, while leaving the plantaris tendon intact. The paratenon was loosely re-approximated and the incision was closed using 4-0 Vicryl sutures. The procedure was then repeated on the contralateral limb to induce bilateral mechanical overload of both the left and right plantaris tendons. Rats were returned to their cage to recover and monitored until ambulatory with free access to food and water. Postoperative analgesia was provided via subcutaneous injection of buprenorphine $(0.03 \mathrm{mg} / \mathrm{kg})$ at $12 \mathrm{~h}$ post-surgery and animals were monitored daily for any signs of pain or distress for 7 days. Age matched male rats served as non-surgical ambulatory control animals for collection of habitually loaded plantaris tendons.

Tissue Collection: Animals were euthanized via induction of bilateral pneumothorax while under isoflurane anesthesia. The plantaris musculotendinous unit was carefully dissected and a sample of the tendon mid-substance isolated by severing its distal insertion at the calcaneus and at its proximal border near the myotendinous junction. The isolated plantaris tendon samples were blotted dry, weighed, and then cut transversely with a scalpel blade into three separate pieces. The mid-portion of the plantaris tendon, allocated to immunohistochemical analysis, was oriented longitudinally on a plastic support, covered with a thin layer of 
optimal cutting temperature (OCT) compound, and rapidly frozen in isopentane cooled on liquid nitrogen. The remaining proximal and distal portions of the plantaris tendon, allocated to mRNA expression and LC-MS/MS analysis respectively, were weighed and then snap frozen in liquid nitrogen. Samples were stored at $-80^{\circ} \mathrm{C}$ until further analysis. Samples from the mid-belly region of the plantaris muscles from these same rats were also collected for analysis and their mediator lipidomic profile is reported separately (48).

Histological Analysis of Tendon Inflammation: Tissue cross-sections $(10 \mu \mathrm{m})$ were cut at $-20^{\circ} \mathrm{C}$ from the mid-portion of OCT embedded plantaris tendons in a cryostat (CryoStar NX50, Thermo Fisher Scientific). Sections were adhered to SuperFrost Plus slides, air dried at room temperature, fixed in ice-cold acetone at $-20^{\circ} \mathrm{C}$ for $10 \mathrm{~min}$. Following air drying to evaporate residual acetone the fixed slides were blocked for $1 \mathrm{~h}$ at room temperature in 10\% normal goat serum (Invitrogen, Thermo Fisher Scientific, 10000C) in phosphate buffered saline (PBS) prior to overnight incubation at $4{ }^{\circ} \mathrm{C}$ with blocking buffer containing primary antibodies raised against HIS48 (Abcam, Ab33760, 1:20), CD68 (Abcam, ab31630, 1:50), and CD163 (Santa Cruz, sc-33560, 1:50), to simultaneously detect rat myeloid cell populations including PMNs, ED1 (M1-like) MФ, and ED2 (M2like) $\mathrm{M} \Phi$ respectively. The following day, slides were washed in PBS and then incubated for $1 \mathrm{~h}$ at room temperature with secondary antibodies including Goat Anti-Mouse IgG1 Alexa Fluor 488 conjugate (Invitrogen, Thermo Fisher Scientific, A21121, 1:500 in PBS), Goat Anti-Mouse IgM Alexa Fluor 555 conjugate (Invitrogen, Thermo Fisher Scientific, A21426, 1:500 in PBS), and Goat Anti-Rabbit IgG (H+L) Alexa Fluor 647 (Invitrogen, Thermo Fisher Scientific, A21245, 1:500 in PBS). Wheat germ agglutinin (WGA) CF405S conjugate (Biotium, 29027, $100 \mu \mathrm{g} / \mathrm{mL}$ in PBS) was also included in the secondary antibody solution in order to label and visualize the extracellular matrix. Following further washing in PBS, slides were mounted using Fluorescence Mounting Medium (Agilent Dako, S302380) and allowed to dry overnight protected from light at room temperature Fluorescent images were captured using a Nikon A1 inverted confocal microscope.

LC-MS/MS Based Metabolipidomic Profiling of Tendon: Plantaris tendon samples were mechanically homogenized in $1 \mathrm{~mL}$ of phosphate buffered saline (PBS) using a bead mill. The tissue homogenates were centrifuged at $3000 \times g$ for $5 \mathrm{~min}$ and the resulting supernatant collected. Supernatants $(0.85 \mathrm{ml})$ were spiked with $150 \mu 1$ methanol containing $5 \mathrm{ng}$ each of 15(S)-HETE-d8, 14(15)-EpETrE-d8, Resolvin D2-d5, Leukotriene B4- 
$\mathrm{d} 4$, and Prostaglandin E1-d4 as internal standards for recovery and quantitation and mixed thoroughly. The samples were then extracted for PUFA metabolites using C18 extraction columns as previously described (48, 57, 58). Briefly, the internal standard spiked samples were applied to conditioned C18 cartridges, washed with $15 \%$ methanol in water followed by hexane and then dried under vacuum. The cartridges were eluted with $2 \times 0.5$ $\mathrm{ml}$ methanol with $0.1 \%$ formic acid and then then eluate was dried under a gentle stream of nitrogen. The residue was re-dissolved in $50 \mu \mathrm{l}$ methanol-25 $\mathrm{mM}$ aqueous ammonium acetate (1:1) and subjected to LC-MS analysis. HPLC was performed on a Prominence XR system (Shimadzu) using Luna C18 $(3 \mu \mathrm{m}, 2.1 \times 150 \mathrm{~mm})$ column as previously described $(59,60)$. The HPLC eluate was directly introduced to electrospray ionization source of a QTRAP 5500 mass analyzer (ABSCIEX) in the negative ion mode and monitored by a Multiple Reaction Monitoring (MRM) method to detect unique molecular ion - daughter ion combinations for each of the lipid mediators using a scheduled MRM around the expected retention time for each compound. Spectra of each peak detected in the scheduled MRM were recorded using Enhanced Product Ion scan to confirm the structural identity. The data were collected using Analyst 1.7 software and the MRM transition chromatograms were quantitated by MultiQuant software (both from ABSCIEX). The internal standard signals in each chromatogram were used for normalization, recovery, as well as relative quantitation of each analyte.

LC-MS/MS data was analyzed using MetaboAnalyst 4.0 (61). Analytes with $>50 \%$ missing values were removed from the data set and remaining missing values were replaced with half of the minimum positive value in the original data set. Heat maps were generated in MetaboAnalyst using the Pearson distance measure and the Ward clustering algorithm following auto scaling of features without data transformation. Volcano and PCA plots were generated in $\mathrm{R}$ following $\log _{2}$ data transformation using the EnhancedVolcano and FactoMineR packages respectively

RNA Extraction and RT-qPCR: Tendon samples were homogenized for 45 seconds at $4 \mathrm{~m} / \mathrm{s}$ in $600 \mu \mathrm{L}$ TRIzol reagent using a Fisherbrand ${ }^{\mathrm{TM}}$ Bead Mill 4 Homogenizer (Thermo Fisher Scientific, 15-340-164) with reinforced $2 \mathrm{~mL}$ tubes (Thermo Fisher Scientific, 15-340-162) and $2.4 \mathrm{~mm}$ metal beads (4 beads/tube) (Thermo Fisher Scientific, 15-340-158). RNA was isolated by Phenol/Chloroform extraction and RNA yield determined using a NanoDrop Spectrophotometer (Nanodrop 2000c, Thermo Fisher Scientific). Genomic DNA was removed 
by incubation with DNase I (Ambion, Thermo Fisher Scientific, AM2222) followed by its heat inactivation. Total RNA (250 ng) was then reverse transcribed to cDNA using SuperScript ${ }^{\mathrm{TM}}$ VILO $^{\mathrm{TM}}$ Master Mix (Invitrogen, 11755-050) and RT-qPCR performed on a CFX96 Real-Time PCR Detection System (Bio-Rad, 1855195) in duplicate $20 \mu \mathrm{L}$ reactions of iTaq ${ }^{\mathrm{TM}}$ Universal SYBR ${ }^{\circledR}$ Green Supermix (Bio-Rad, 1725124) with $1 \mu \mathrm{M}$ forward and reverse primers (Table 1). Relative mRNA expression was determined using the $2^{-\Delta \Delta C T}$ method with $B 2 m$ serving as an endogenous control.

Statistics: Data is presented as the mean \pm SEM with raw data from each individual tendon sample shown. Statistical analysis was performed in GraphPad Prism 7. Between group differences were tested by two-tailed unpaired students t-tests (2 groups) or by a one-way analysis of variance (ANOVA) followed by pair-wise HolmSidak post-hoc tests ( $\geq 3$ groups). For time-course experiments, multiple comparison testing was made compared to a single control group of tendons obtained from ambulatory control rats that did not undergo surgery. $p \leq 0.05$ was used to determine statistical significance. 


\section{Results:}

\section{Lipid Mediator Profile of Tendon}

We initially examined the basal lipid mediator profile of habitually loaded tendons via LC-MS/MS based targeted metabolipidomics. A total of sixty-four individual lipid mediator species were reliably detected (signal to noise ratio $>3$ and peak quality $>0.2$ in at least $50 \%$ of samples) in plantaris tendon homogenates from rats undergoing normal cage activity (Figure 1A). These included many bioactive metabolites of n-6 AA derived via the COX-1 and 2 pathways [prostaglandins, e.g. $\mathrm{PGD}_{2}, \mathrm{PGE}_{2}, \mathrm{PGF}_{2 \alpha}, \mathrm{PGI}_{2}$ (measured as its inactive nonenzymatic hydrolysis product 6-keto-PGF $1_{\alpha}$ ) and thromboxanes [e.g. TXA 2 (measured as its inactive nonenzymatic hydrolysis product $\mathrm{TXB}_{2}$ ) and the related thromboxane synthase metabolite 12-hydroxyheptadecatrienoic acid (12-HHTrE)] (Figure 1A, Supplemental Table 1A). Monohydroxylated AA metabolites of the three major mammalian lipoxygenase enzymes (5-, 12, and 15-LOX) were also detected including 5-, 12-, 15hydroxy-eicosatetraenoic acids (HETEs)] (Figure 1A, Supplemental Table 1B). Finally, AA metabolites of the epoxygenase (CYP 450) pathway were present in tendon including 5(6)-, 8(9)-, 11(12)-, 14(15)-epoxyeicosatrienoic acid regioisomers (EpETrEs) (Figure 1A, Supplemental Table 1C). In addition to these eicosanoids, several metabolites of the parent n-6 PUFA linoleic acid (LA, 18:2n-6) were highly abundant in tendon homogenates, including those derived via both the LOX pathway [9- and 13-hydroxy-octadecadienoic acid (HODEs) and downstream oxo-octadecadienoic acids (OxoODEs)] and CYP pathway [9(10)- and 12(13)-epoxyoctadecenoic acids (EpOMEs) and downstream dihydroxy-octadecenoic acids (DiHOMEs)] (Figure 1A).

Many n-3 PUFA metabolites were also detected in tendon, albeit generally at relatively lower concentrations than the above n-6 PUFA products. This included the DHA-derived SPM, resolvin D1 (RvD1), as well as 17-hydroxy-docosahexaenoic acid (17-HDoHE), the primary intermediate 15-LOX metabolite of n-3 DHA produced during the initial step of D-series resolvin biosynthesis. Other SPMs including the E-series resolvins (e.g. RvE1), protectins (e.g. PD1), and maresins (e.g. MaR1) were generally below the limits of detection in resting tendon homogenates (Supplemental Table 1D). Nevertheless, key pathway markers in the biosynthesis of the E-series resolvins [(18-hydroxy-eicosapentaenoic acid (18-HEPE)] and maresins [14- 
hydroxy-docosahexaenoic acid (14-HDoHE)] were detected. Finally, CYP pathway derived epoxides of n-3 PUFAs including EPA [5(6)-, 8(9)-, 11(12)-, 14(15)-, 17(18)-epoxy-eicosatetraenoic acid (EpETEs)] and DHA [7(8)-, 10(11)-, 13(14)-, 16(17)-, 19(20-epoxy-docosapentaenoic acid (EpDPE)] were also present within habitually loaded tendons. These data reveal a wide range of novel bioactive lipid mediators within healthy tendon tissue in-vivo for the first time.

\section{Functionally Associated Musculoskeletal Tissues Exhibit Highly Distinct Metabolipidomic Profiles}

The complete LC-MS/MS profile of plantaris skeletal muscle samples from these same rats has been previously published (48). Unsupervised principle component analysis (PCA) revealed that the mediator lipidome of the tendon samples analyzed here was highly distinct from that of the habitually loaded plantaris muscles from these same rats (Figure 1B). The corresponding loading plots displaying some representative lipid mediators from each major enzymatic biosynthetic pathway that defined the distinct lipid mediator profiles of muscle and tendon samples are shown in Figure 1C. When pooled over these major biosynthetic pathways, $72 \%$ of the overall mediator lipidome of muscle comprised CYP pathways metabolites (e.g. EpETrEs, EpETEs, and EpDPEs), with only $7 \%, 10 \%$, and $3 \%$ of total metabolites derived from the COX (e.g. PGE 2 ), 12-LOX (e.g. 12-HETE), and 15LOX (e.g. 15-HETE) pathways respectively (Figure 1D). In contrast, the tendon mediator lipidome overwhelmingly comprised COX (42\%), 12-LOX (28\%), and 15-LOX (6\%) pathway metabolites, with only 9\% of total lipid mediators derived from the CYP pathway (Figure 1D). Despite these differences in the relative composition of mediator lipidome between tissues, total lipid mediator concentration was similar between muscle and tendon when normalized to tissue mass $(\sim 1.2 \mathrm{pmol} / \mathrm{mg})$ (Figure $1 \mathrm{D}-\mathrm{E})$.

Parametric statistical analysis revealed that of the total ninety-four individual lipid mediators that were detected in either tendon or muscle tissue, thirty-five were significantly enriched in tendon $(\mathrm{p}<0.05$ and $>1.5$ fold), while seventeen were significantly enriched in muscle ( $\mathrm{p}<0.05$ and $>1.5$-fold) (Figure $1 \mathrm{~F}$ ). When compared to muscle, tendon contained relatively lower absolute concentrations of anti-inflammatory CYP pathway metabolites including many epoxide products of AA [5(6)-, 8(9)-, 11(12)-, and 14(15)-EpETrEs], EPA [8(9)-, 14(15)- \& 17(18)-EpETEs], and DHA [7(8)-, 10(11)-, 13(14)-, 16(17)-, and 19(20)-EpDPEs]. 20-HETE, a $\omega-$ 
hydroxylase CYP metabolite of AA was similarly lacking in tendon. Finally, the primary n-3 EPA product produced during biosynthesis of the E-series resolvins, 18-HEPE, which is endogenously derived via the CYP pathway (62), was also significantly lower in tendon than muscle. On the other hand, tendon contained far higher concentrations than muscle of many COX pathway metabolites including the major AA-derived thromboxanes $\left(\mathrm{TXB}_{2}\right.$ and 12-HHTrE) and prostaglandins $\left(\mathrm{PGD}_{2}, \mathrm{PGE}_{2}, \mathrm{PGF}_{2 \alpha}, 6\right.$-keto- $\left.\mathrm{PGF}_{1 \alpha}\right)$. Many downstream secondary and tertiary prostaglandin metabolites of the 15-hydroxy-prostaglandin dehydrogenase (15-PGDH) and 15-oxoprostaglandin $\Delta^{13}$-reductase pathways including 15-keto $\mathrm{PGE}_{2}, 15$-keto $\mathrm{PGF}_{2 \alpha}$, 13,14-dihydro-15-keto $\mathrm{PGE}_{2}$, 13,14-dihydro-15-keto $\mathrm{PGD}_{2}$, and 11-dihydro-2,3-dinor $\mathrm{TXB}_{2}$ were also enriched in tendon, as were the cyclopentenone prostaglandins including $\mathrm{PGJ}_{2}, \Delta^{12}-\mathrm{PGJ}_{2}$, and 15 -deoxy- $\Delta^{12,14}-\mathrm{PGJ}_{2}\left(15 \mathrm{~d}-\mathrm{PGJ}_{2}\right)$ (which are nonenzymatically derived from $\mathrm{PGD}_{2}$ ). Many LOX-pathway metabolites including 5-, 11-, 12-, and 15-HETEs, 12and 15-oxoETEs, 11- and 12-HEPEs, 9- and 13-HODEs, 9- and 13-HOTrEs, and 5S,12S-DiHETE were also relatively enriched in tendon. Consistently, the DHA-derived SPM RvD1, which is produced by the sequential action of the 15- and 5-LOX pathways, was detected in habitually loaded tendons, but was below the limits of detection in muscle (as previously reported) (48).

\section{Local Shifts in Lipid Mediator Biosynthesis in Response to Synergist Ablation-Induced Tendon Overuse}

In order to examine local shifts in lipid mediator biosynthesis in response to tendon overuse, we surgically removed the gastrocnemius/soleus (Achilles) tendon to induce compensatory mechanical overload upon the synergistic plantaris musculotendinous unit. Functionally overloaded plantaris tendons were then collected for analysis by LC-MS/MS at 3-, 7-, and 28-days following synergist ablation surgery (Figure 2).

When compared to control plantaris tendons obtained from age and sex matched ambulatory rats, intratendinous concentrations of eighteen individual lipid mediator species were significantly modulated at day 3 of synergist ablation-induced plantaris tendon overuse (Figure 2A). This included increased concentrations of the $\mathrm{COX} /$ thromboxane synthase products $\mathrm{TXB}_{2}$ and $12-\mathrm{HHTrE}$, as well as the $\mathrm{COX} /$ prostaglandin $\mathrm{E}$ synthase product, $\mathrm{PGE}_{2}$, as well as its downstream enzymatic inactivation products $15-$ keto $\mathrm{PGE}_{2}$ and 13,14-dihydro-15keto $\mathrm{PGE}_{2}$. The $\mathrm{COX} /$ prostaglandin D synthase product $\mathrm{PGD}_{2}$ was simultaneously reduced by $50 \%$, while 
$\mathrm{COX} /$ prostaglandin $\mathrm{F}$ and I synthase products $\mathrm{PGF}_{2 \alpha}$ and $\mathrm{PGI}_{2}$ (measured as 6-keto-PGF $1 \alpha$ ) remained unchanged in parallel at this time-point. Primary 15-LOX metabolites of AA (15-HETE) and EPA (15-HEPE) were additionally increased at day 3 post surgery, with a similar non-significant trend also seen for 17-HDoHE ( $p=0.057$ ), the analogous 15 -LOX product of $n-3$ DHA. In contrast, most major metabolites of the 5-LOX, 12LOX, and CYP pathways remained unchanged in tendon at day 3 following synergist ablation.

A total of thirty lipid mediators were significantly modulated following 7 days of tendon overuse (Figure 2B). This included further increases in many of the same lipid mediators seen at day 3 (e.g. $\mathrm{TXB}_{2}, \mathrm{PGE}_{2}, 15-$ HETE) as well as additional more delayed increases in $\mathrm{PGD}_{2}$ and its downstream enzymatic inactivation product 13,14-dihydro-15-keto $\mathrm{PGD}_{2}$. Similarly, $\mathrm{PGF}_{2 \alpha}$ and its downstream enzymatic inactivation products 15-keto$\mathrm{PGF}_{2 \alpha}$ and 13,14-dihydro-15-keto $\mathrm{PGF}_{2 \alpha}$ were increased, as was the fifth primary prostanoid $\mathrm{PGI}_{2}$ (measured as 6-keto-PGF $1 \alpha$ ). Finally, the Series-J cyclopentenone prostaglandins, including $\mathrm{PGJ}_{2}, \mathrm{D} 12-\mathrm{PGJ}_{2}$, and $15 \mathrm{~d}-\mathrm{PGJ}_{2}$, were produced together with their precursor $\mathrm{PGD}_{2}$ at day 7 following synergist ablation.

By 28-days of tendon overuse, a total of thirty-eight individual lipid mediators differed significantly from ambulatory control tendons (Figure $2 \mathrm{C})$. This included persistent elevation of all major COX-metabolites $\left(\mathrm{TXB}_{2}\right.$, $\mathrm{PGE}_{2}, \mathrm{PGD}_{2}, \mathrm{PGF}_{2 \alpha}$, and 6-keto- $\mathrm{PGF}_{1 \alpha}$ ) and their respective downstream metabolic inactivation products of the 15-PGDH pathway (e.g. 15-keto and 13,14-dihydro-15-keto PGs). The primary 5-LOX metabolite of n-6 AA, 5HETE, and its metabolite 5-oxoETE, also exhibited a delayed increase at this time-point, although related 5-LOX metabolites derived from the downstream $\mathrm{LTA}_{4}$ hydrolysis pathway, including $\mathrm{LTB}_{4}$ and 12-oxoLTB 4 , remained below the limits of detection. Finally, CYP pathway derived epoxides of n-6 AA including 5(6)-, 11(12)-, and 14(15)-EpETrE were increased at day 28 of tendon overuse, as were some analogous CYP metabolites of EPA [11(12)-, 13(14)-, and 17(18)-EpETEs].

The temporal shifts in absolute tendon lipid mediator concentrations when pooled over major enzymatic biosynthetic pathways are summarized in Figure 2D and the time-course kinetics of the top 25 individual lipid mediator species that were modulated by tendon overuse are shown in Figure 2E. The entire quantitative tendon LC-MS/MS data set for each individual lipid mediator profiled is shown in Supplemental Table 1. Significant 
increases over time were found for pooled metabolites of the COX, 8-LOX, 15-LOX, and CYP pathway, as well as for pooled concentrations of detected bioactive SPMs (Figure 2D). A similar trend was also observed for pooled metabolites of the 5-LOX pathway, although this failed to reach statistical significance ( $\mathrm{p}=0.076$, Figure $2 \mathrm{D})$. Despite a more delayed increase in local concentrations of lipid mediators with anti-inflammatory and proresolving actions, the overwhelming predominance of biosynthesis of classical pro-inflammatory COX pathway metabolites in mechanically overloaded plantaris tendon resulted in a progressive reduction in the percentage of the overall mediator lipidome that was derived from the LOX, CYP and SPM pathways over time (Figure 2F). Because of this, the proportion of the overall mediator lipidome consisting of classical pro-inflammatory eicosanoids derived from the COX pathway increased from $42 \%$ in control plantaris tendons from ambulatory rats (Figure 1E) to encompass $54 \%, 74 \%$ and $60 \%$ of the mediator lipidome at day 3,7 and 28 of tendon overuse respectively (Figure $2 \mathrm{~F})$.

\section{Local Leukocyte Responses to Tendon Overuse}

To investigate the relationship between shifts in intratendinous lipid mediator concentrations as determined by LC-MS/MS based profiling and cellular inflammation of tendon, we performed immunohistochemical staining of cross-sections of ambulatory control and mechanically overloaded plantaris tendons with antibodies to detect infiltrating myeloid cell populations including PMNs (HIS48 ${ }^{+}$cells), inflammatory ED1 monocytes/MФ (CD68 ${ }^{+}$cells), and resident/M2-like ED2 MФ (CD163 cells) (Figure 3A).

Control plantaris tendons from ambulatory rats were apparently devoid of resident leukocytes based on cellular expression of these markers. In contrast and as previously reported (48), many resident ED2 M $\Phi\left(\mathrm{CD} 68^{-} \mathrm{CD} 163^{+}\right.$ cells) were seen scattered throughout the internal connective tissues (e.g. perimysium and endomysium) of plantaris muscle cross-sections from these same rats. These data suggest that unlike functionally associated skeletal muscle, tendon does not appear to possess a substantial resident myeloid cell population.

At day 3 of tendon overuse there was an accumulation of many PMNs (HIS48 ${ }^{+}$cells) (Figure $3 \mathrm{~A}$ and 3B) and $\mathrm{ED} 1 \mathrm{M} \Phi\left(\mathrm{CD}^{+} 8^{+} \mathrm{CD} 163^{-}\right.$cells) (Figure 3A and 3C) throughout the expanded tissue space at the plantaris tendon periphery. ED1 M $\Phi$ were also be seen within the peripheral edges of the dense tendon core at this time- 
point, appearing to originate from within the epitenon (Figure 4A). A more modest increase in the histological presence of $\mathrm{ED} 2 \mathrm{M} \Phi\left(\mathrm{CD} 68^{-} \mathrm{CD} 163^{+}\right.$cells) was also seen throughout the tendon periphery, but not the tendon core, at this time-point (Figure 3A and 3D). By day 7 of tendon overuse, there was a robust histological presence of large numbers of $\mathrm{ED} 1 \mathrm{M} \Phi\left(\mathrm{CD} 68^{+} \mathrm{CD} 163^{-}\right.$cells $)$throughout the newly forming connective tissue layer that surrounded the original tendon (e.g. the neotendon matrix), although ED2 M $\Phi$ were no longer significantly increased (Figure 3A). Many ED1 M $($ but not ED2 $M \Phi$ ) were also seen scattered throughout the dense original tendon core at day 7 following synergist ablation (Figure 4A). By day 28 of tendon overuse, few infiltrating myeloid cells remained, in particular within the tendon core (Figure 4A). Nevertheless, some CD68 ${ }^{+} \mathrm{CD} 63^{-}$cells could still be seen scattered throughout the peripheral neotendon matrix in the majority of samples analyzed (Figure 3C). Only a very small proportion of the $\mathrm{CD} 68^{+}$cells within mechanically overloaded tendons coexpressed the CD163 antigen at all time-points between day 3 and 28 of tendon overuse (Figure 3A, 3D and 4A).

\section{Expression of Inflammation-Related Genes in Tendon Following Synergist Ablation}

Despite the apparent lack of histological presence of resident myeloid cells, mRNA encoding the general myeloid cell marker CD11b (Itgam), inflammatory monocyte/MФ markers CD68 (Cd68) and EMR1 (the rat analog of F4/80, Adgre1), as well as the resident/M2-like MФ markers CD163 (Cd163) and CD206 ( $\mathrm{Mrcl}$ ) were expressed at detectable levels in resting plantaris tendon (Figure 5). Following synergist ablation surgery, tendon mRNA expression of $\mathrm{CD} 11 \mathrm{~b}$ was increased 10 -fold above ambulatory control tendons at day 3 , remained elevated by 3.5 fold at day 7, but no longer differed from control levels by day 28 (Figure 5A). Similarly, expression of the MФ markers CD68 (Figure 5B) and F4/80 (Figure 5C) both increased 15-fold and 10-fold respectively at day 3, remained increased by 3.5-fold at day 7, but had returned to basal levels by day 28 of recovery. CD163 mRNA did not differ significantly from control tendons at any time-point, but was 3.5 fold higher at day 3 of tendon overuse when compared to day 28 of recovery ( $\mathrm{p}=0.023$ ) (Figure 5D). The alternate M2-like M $\Phi$ marker CD206 $(M r c 1)$ was also increased 5-fold at day 3 following synergist ablation, but no longer differed from control tendons at either day 7 or 28 (Figure 5E). Expression of both the constitutive COX-1 (Ptgs 1 ) and inducible COX-2 (Ptgs2) isoform mRNA was detectable in ambulatory control plantaris tendons. At day 3 of tendon overuse, COX-2 mRNA expression was increased by 4-fold (Figure 5G), but COX-1 mRNA remained unchanged (Figure 5F). 
351 Neither COX-1 nor COX-2 mRNA expression differed significantly from control tendons by day 7 or 28 of 352 continued tendon overuse.

\section{Changes in Tendon Mass and Total RNA Content in Response to Mechanical Overuse}

overuse, while tendon mass remained unchanged (Table 2). This resulted in a 3-fold increase in the total RNA content of the overloaded plantaris tendon ( $\mu \mathrm{g}$ RNA/tendon). Both intratendinous RNA concentration and total tendon RNA content remained increased at seven days of overuse, while tendon mass was still not yet significantly altered (1.7-fold, $\mathrm{p}=0.17$ ). By 28 days following synergist ablation a significant increase in the mass of the overloaded plantaris tendon was observed (2.2-fold). At this time-point, intratendinous RNA concentration no longer differed from that of ambulatory control tendons, but the total RNA content of the overloaded plantaris tendon remained increased by approximately 3 -fold. These data show clear changes in the total RNA content of the mechanically overloaded plantaris tendon which accompany the increased cellularity resulting from leukocyte infiltration and likely also tenocyte proliferation. On this basis, it is important to consider the relative changes in mRNA expression of genes of interest (at an equivalent RNA input) in light of the marked changes in tendon total RNA content that occur following synergist ablation. 


\section{Discussion}

Here we profiled local changes in lipid mediator biosynthesis following synergist ablation-induced plantaris tendon overuse. A wide range of bioactive metabolites of the COX, LOX, and CYP pathways were detected in tendon for the first time. When compared to skeletal muscle, tendons were enriched in classical proinflammatory eicosanoid metabolites of the COX and 12-LOX pathways, but relatively lacking in CYP-pathway derived anti-inflammatory lipid epoxides. Three days of tendon overuse induced a robust local inflammatory response characterized by heightened biosynthesis of $\mathrm{PGE}_{2}$ and $\mathrm{TXB}_{2}$, increased expression of inflammationrelated genes, and peritendinous infiltration of both PMNs and MФ. There was more delayed production of $\mathrm{PGD}_{2}$, $\mathrm{PGF}_{2 \alpha}, 6-$ keto-PGF $1 \alpha$ at day 7 at which time MФ became the predominant myeloid cell type within tendon. Proresolving lipid mediator biosynthesis was also increased following tendon overuse; however, there was a persistent reduction in the ratio of SPMs and their related LOX-derived pathway markers relative to the COXderived prostaglandins over time. This overwhelming predominance of pro-inflammatory eicosanoids in tendon was associated with incomplete resolution of inflammation even at 28 days following synergist ablation.

The marked increase in $\mathrm{PGE}_{2}$ in response to plantaris tendon overuse observed in the current study supports prior studies showing that local $\mathrm{PGE}_{2}$ concentrations increase in response to an acute bout of exercise in both mice $(28,29)$ and humans $(30,31)$. While most prior studies in tendon have focused exclusively on PGE 2 , we show for the first time that overloaded tendons also produce substantial amounts of the other three major prostaglandins, $\mathrm{PGD}_{2}, \mathrm{PGF}_{2 \alpha}$, and $\mathrm{PGI}_{2}$ (measured as 6-keto-PGF $1 \alpha$ ). Biosynthesis of $\mathrm{TXA}_{2}$, the fifth major primary bioactive metabolite of the COX pathway, was also increased in response to synergist ablation (based on measurement of $\mathrm{TXB}_{2}$ ), which is consistent with an earlier human study in which peritendinous $\mathrm{TXB}_{2}$ increased following a single bout of exercise (63). Major cellular sources of specific prostanoids include blood platelets $\left(\mathrm{TXA}_{2}\right)(64), \mathrm{PMNs}\left(\mathrm{TXA}_{2}\right.$ and $\left.\mathrm{PGE} 2\right)(65)$, mast cells $\left(\mathrm{PGD}_{2}\right)(66)$ monocytes/MФ $\left(\mathrm{PGE}_{2}\right)(67)$, and vascular endothelial cells $\left(\mathrm{PGI}_{2}\right)(68)$. Thus, it is likely that the PMNs and/or M $\Phi$ that accumulated in tendon in the current study contributed substantially to the intratendinous prostaglandin response to mechanical overload. Although not assayed here, mast cells have also been found to appear locally in response to tendon overuse in prior studies and may thus contribute substantially to the $\mathrm{PGD}_{2}$ response $(11,16)$. In addition to leukocytes, fibroblasts 
themselves can also produce prostaglandins, most notably $\mathrm{PGE}_{2}(69)$, but also $\mathrm{PGI}_{2}(70)$ and TXA2 (71). Indeed, resident tendon fibroblasts (tenocytes) express both COX-1 and 2 (72), enabling them to locally produce and release $\mathrm{PGE}_{2}$ in response to mechanical stimulation in-vitro (73). Consistent with our data, recent studies employing LC-MS/MS based lipid mediator profiling show that human tenocytes cultured in-vitro also produce substantial amounts of the other major prostanoids $\left(\mathrm{PGE}_{2}>\mathrm{PGD}_{2}>\mathrm{PGF}_{2 \alpha}>\mathrm{TXB}_{2}\right)(52-55)$. Although $\mathrm{PGI}_{2}$ does not appear to be a major product of isolated healthy tenocytes cultured in-vitro, stromal cells isolated from diseased human tendons do produce large amounts of $\mathrm{PGI}_{2}$ (74). While tendon cells can themselves synthesize prostaglandins, even in the absence of inflammation, mechanically stimulated tenocytes release far greater amounts of $\mathrm{PGE}_{2}$ when allowed to interact with $\mathrm{M} \Phi$ than when cultured in isolation (35). Therefore, cross-talk between infiltrating myeloid cell populations such as PMNs and M $\Phi$ with resident tendon cells likely drives the robust prostaglandin response to tendon overuse.

While all major prostanoids were responsive to tendon overuse in the current study, notably they exhibited distinct class-specific temporal responses. Peak PMN infiltration at day 3 of tendon overuse was accompanied by a rapid initial increase in production of $\mathrm{PGE}_{2}$ and $\mathrm{TXB}_{2}$, while $\mathrm{PGD}_{2}$ was simultaneously reduced. Subsequently, $\mathrm{PGD}_{2}$ exhibited a more delayed increase from this initial decline to reach concentrations 4-fold above ambulatory controls by day 7 of tendon overuse, at which time the series-J cyclopentenone prostaglandins including $P G J_{2}$, $\Delta^{12}-\mathrm{PGJ}_{2}, 15 \mathrm{~d}-\mathrm{PGJ}_{2}$ [which are non-enzymatically derived from $\mathrm{PGD}_{2}(75)$ ] were also increased. In contrast to $\mathrm{PGE}_{2}$, which primarily stimulates inflammation $(76), \mathrm{PGD}_{2}$ rather exerts anti-inflammatory actions directly via the DP1 prostanoid receptor, as well as secondary to the formation of downstream cyclopentenone prostaglandins such as $15 \mathrm{~d}-\mathrm{PGJ}_{2}$ which are purported endogenous peroxisome proliferator-activated receptors (PPAR) ligands (77). Thus, overall our data are consistent with prior studies demonstrating a transition from a pro-inflammatory, $\mathrm{PGE}_{2}$-dominated eicosanoid profile during the development of inflammation to a more anti-inflammatory, $\mathrm{PGD}_{2}$ /cyclopentenone-dominated eicosanoid profile during the resolution phase (78). 
LOX. In cells that express $\mathrm{LTA}_{4}$ hydrolase, LTA4 undergoes subsequent conversion to LTB4. Alternatively, 5HpETE can undergo further metabolism via reduction or dehydration to 5-HETE and 5-oxoETE, respectively. Both 5-HETE and 5-oxoETE were markedly increased in tendon in response to synergist ablation in the current study, but $\mathrm{LTB}_{4}$ and its downstream inactivation product 12-oxo $\mathrm{LTB}_{4}$ were both below the limits of detection. These data show that heightened mechanical loading of tendon in-vivo clearly does increase local biosynthesis of 5-LOX metabolites but question whether $\mathrm{LTB}_{4}$ is a major metabolite produced in tendon. Consistently, recent studies by others utilizing LC-MS/MS also failed to detect $\mathrm{LTB}_{4}$ in isolated human tenocytes in-vitro (52-54).

In addition to producing pro-inflammatory leukotrienes, the LOX pathways play important roles in the formation of recently identified SPM families of lipid mediators with pro-resolving actions (80). For example, lipoxin biosynthesis involves the initial production of 15-HETE, a 15-LOX metabolite of $\mathrm{n}-6 \mathrm{AA}$, which is then released and taken up by 5 -LOX expressing cells (e.g. PMNs) to be converted to LXA4 and LXB $(81,82)$. In analogous n-3 PUFA generated pathways, 17-HDoHE (a 15-LOX metabolite of n-3 DHA) and 18-HEPE (a CYP metabolite of n-3 EPA) are converted to the D-series resolvins (83) and E-resolvins (62) respectively via the sequential action of 5-LOX. Finally, 14-HDoHE (a 12-LOX metabolite of DHA) serves as the primary intermediate produced during biosynthesis of the most recently identified maresin family of SPMs (42). We show here that tendon contains detectable levels of all four of these major monohydroxylated SPM pathway markers. Tendon overuse markedly increased local concentrations of 15-HETE, 18-HEPE, and 17-HDoHE. On the other hand, 14-HDoHE was unchanged in response to tendon overuse, as were the related 12-LOX metabolites of AA (12-HETE) and EPA (12-HEPE). Overall these data show that, 15-LOX derived SPM biosynthetic pathways are induced in the mechanically overloaded plantaris tendon, like they are in functionally associated muscle (48). In contrast, metabolites of the 12-LOX pathway which are major metabolites produced within functionally overloaded skeletal muscle (48), do not appear to be responsive to heightened mechanical loading of tendon.

We also detected RvD1 in tendon, but its concentration was apparently not influenced by tendon overuse. In contrast, RvD2, protectin D1, and RvD6 were below the limits of detection in tendons from ambulatory rats, but did increase in concentration to become detectable following synergist ablation. Other SPMs including the lipoxins ( $\mathrm{LXA}_{4}$ and $\mathrm{LXB}_{4}$ ), E-series resolvins (RvE1 and RvE3), and maresins (MaR1) were generally below the 
limits of detection of our LC-MS/MS assay irrespective of time-point. Overall our data are consistent with recent work showing that isolated human tendon stromal cells cultured in-vitro may produce LOX-derived SPMs, in addition to classical pro-inflammatory eicosanoids (52-54). However, similar to the case with muscle tissue (48), tendon homogenates in-vivo clearly contain far greater concentrations of primary LOX derived monohydroxylated intermediates in SPM pathways than the bioactive SPMs themselves. This may be attributable to the highly transient nature of mature SPMs, their relative enrichment in the extracellular vs intracellular environment, and/or their naturally low concentrations relative to the limits of detection of the LC-MS/MS assay used here.

We found that plantaris tendons from ambulatory rats were apparently devoid of resident myeloid cells. This finding is consistent with many prior studies that have reported that healthy tendons do not appear to contain a notable resident $\mathrm{M} \Phi$ population $(9,10,14-17,51,84)$. In contrast, a recent study described the presence of 'tenophages' residing within the dense core of Achilles tendons of healthy ambulatory mice that expressed M $\Phi$ lineage markers together with the tenocyte lineage marker scleraxis (85). As a positive control (86), we could easily observe many resident $\mathrm{ED} 2 \mathrm{M} \Phi\left(\mathrm{CD}^{-} \mathrm{CD} 163^{+}\right.$cells $)$scattered throughout the perimysium and endomysium of plantaris muscles from these same rats (48). Plantaris tendons did clearly contain resident cells that expressed detectable amounts of mRNA encoding these and other immune cell markers as determined by RT-qPCR. Interpretation of this finding is complicated, however, by prior studies showing that various nonmyeloid cell types, including fibroblasts, may also express low levels of common myeloid lineage markers such as CD68 (87). Thus, it currently remains unclear whether a bonafide resident MФ population exists within the dense core of the tendon proper or rather whether populations of resident tenocytes also express relatively lower amounts of markers commonly used to identify myeloid cells. If such cells do reside in the healthy tendon our data show that either the proteins are not synthesized or are very rapidly degraded resulting in expression levels of these markers far lower than those $М \Phi$ that are well-established to reside within skeletal muscle.

Unlike in habitually loaded tendon, we observed a robust peritendinous infiltration of both PMNs and MФ following synergist ablation surgery. These data are consistent with early studies in which repetitive kicking exercise in rabbits was shown to result in Achilles paratendinitis $(13,88)$. In a series of later studies inflammatory 
bioRxiv preprint doi: https://doi.org/10.1101/2021.01.08.425901; this version posted January 9, 2021. The copyright holder for this preprint (which was not certified by peer review) is the author/funder, who has granted bioRxiv a license to display the preprint in perpetuity. It is made available under aCC-BY 4.0 International license.

ED1 monocytes/MФ (CD68 ${ }^{+}$cells) were also shown to infiltrate peritendinous tissues of the upper limb in response to repetitive reaching/grasping activity in rats, (14-17). While PMNs were specifically localized to the tendon periphery, interestingly we did observe a more delayed increase in $\mathrm{M} \Phi$ within the dense tendon core in the current study. This finding is consistent with a recent report in which $\mathrm{CD} 68^{+}$cells were shown to infiltrate within the core of the Achilles tendon proper following 3-weeks of daily intensive treadmill running in mice (10). To our knowledge, only a single prior study has quantified intratendinous ED2 M $\Phi\left(\mathrm{CD} 163^{+}\right.$cells) in response to tendon overuse (14). In this study, repetitive upper extremity reaching and grasping in rats resulted in robust infiltration of palmer and forearm tendons by $\mathrm{ED} 1 \mathrm{M} \Phi\left(\mathrm{CD} 68^{+}\right.$cells $)$between 3-6 weeks of overuse, with no change in $\mathrm{ED} 2 \mathrm{M} \Phi\left(\mathrm{CD} 163^{+}\right.$cell $)$number at this time-point $(14)$. Nevertheless, there was a more modest increase in $\mathrm{ED} 2 \mathrm{M} \Phi\left(\mathrm{CD} 163^{+}\right.$cells) in the forelimb tendons by weeks 6-8 of continued overuse (14). Overall, our results following synergist ablation appear most similar to prior studies of intratendinous injection of collagenase, in which only a modest and transient increase in tendon $\mathrm{CD}_{163^{+}}$cells occurred at day 3 post-injury $(7,89)$.

A single bout of resistance exercise in humans results in a transient increase in serum concentrations of many lipid mediators (57). Many of these same lipid mediators also transiently increase within the exercised musculature of human subjects following an acute bout of muscle damaging (eccentric) contractions, suggesting that injured muscle cells may contribute to the systemic lipid mediator response to exercise stress (58). Consistent with this hypothesis, rodent experimental models of muscle injury were recently found to markedly increase intramuscular lipid mediators $(47,48)$. However, aerobic exercise, which is generally not thought to inflict substantial muscle damage, was also recently shown to result in marked increases in plasma lipid mediator concentrations $(90,91)$. The remarkable capacity of mechanically overloaded tendon to produce bioactive lipid mediators identified in the current study suggests that tendon may also be an important and underappreciated cellular source of systemic lipid mediator to exercise (92). Indeed, biopsy samples obtained from human patellar tendons were previously found to express far greater amounts of COX-1 and -2 mRNA when compared to those obtained from the quadriceps muscle (93). Earlier rodent studies also showed that tendons and associated intramuscular connective tissues expressed prostaglandin biosynthetic enzymes much more robustly than the myofibers that make up the bulk of muscle (94). Consistent with these prior studies, we found that the plantaris 
tendon homogenates analyzed here were greatly enriched in prostaglandins when compared to muscle tissue (48).

Overall, these data suggest that muscle-associated connective tissues are likely a key cellular source of bioactive lipid mediators that may serve as autocrine/paracrine signaling molecules between tendon and/or muscle fibroblasts and functionally associated muscle and tendon cells. Similarly, muscle and/or tendon derived lipid mediators may potentially exert cross-organ endocrine actions following their systemic release from the mechanically overloaded musculotendinous unit.

In conclusion, we show for the first time that tendon contains a diverse array of bioactive lipid mediators derived from the COX, LOX and CYP pathways, local biosynthesis of many of which is markedly increased in response to mechanical overuse. When compared to muscle, tendons are greatly enriched in COX and LOX metabolites, but is relatively lacking in products of the CYP pathway. A rapid increase in local concentrations of $\mathrm{TXB}_{2}$ and $\mathrm{PGE}_{2}$ in mechanically overloaded tendons accompanies peritendinous infiltration of PMNs. The subsequent a more delayed increase in intratendinous anti-inflammatory/pro-resolving mediators is accompanied by a progressive PMN clearance and transition to a predominance of $M \Phi$. Despite this, the SPM response appears insufficient to counteract development of chronic tendon inflammation as evidenced by incomplete resolution of the inflammatory response even at 28 days of continued tendon overuse.

\section{Author contributions:}

J.F.M conceived the study. S.V.B and K.R.M and supervised the work. J.F.M and K.B.S designed the experiments. J.F.M and D.C.S performed the experiments. J.F.M and K.R.M analyzed the data. J.F.M prepared the figures and wrote the manuscript with input from all authors.

\section{Acknowledgments:}

This work was supported by the Glenn Foundation for Medical Research Post-Doctoral Fellowship in Aging Research (JFM) the University of Michigan Department of Orthopedic Surgery, and the National Institutes of Health (NIH) under the awards R01 (AG050676) (SVB), PO1 (AG051442) (SVB), P30 (AR069620) (SVB) and S10 (RR027926) (KRM). 


\section{References:}

1. Thorpe, C. T., and Screen, H. R. (2016) Tendon Structure and Composition. Adv Exp Med Biol 920, 310

2. Kongsgaard, M., Reitelseder, S., Pedersen, T. G., Holm, L., Aagaard, P., Kjaer, M., and Magnusson, S. P. (2007) Region specific patellar tendon hypertrophy in humans following resistance training. Acta Physiol (Oxf) 191, 111-121

3. Abat, F., Alfredson, H., Cucchiarini, M., Madry, H., Marmotti, A., Mouton, C., Oliveira, J. M., Pereira, H., Peretti, G. M., Romero-Rodriguez, D., Spang, C., Stephen, J., van Bergen, C. J. A., and de Girolamo, L. (2017) Current trends in tendinopathy: consensus of the ESSKA basic science committee. Part I: biology, biomechanics, anatomy and an exercise-based approach. J Exp Orthop 4, 18

4. Wojciak, B., and Crossan, J. F. (1993) The accumulation of inflammatory cells in synovial sheath and epitenon during adhesion formation in healing rat flexor tendons. Clin Exp Immunol 93, 108-114

5. Kang, H. J., Park, B. M., Hahn, S. B., and Kang, E. S. (1990) An experimental study of healing of the partially severed flexor tendon in chickens. Yonsei Med J 31, 264-273

6. Enwemeka, C. S. (1989) Inflammation, cellularity, and fibrillogenesis in regenerating tendon: implications for tendon rehabilitation. Phys Ther 69, 816-825

7. Marsolais, D., Cote, C. H., and Frenette, J. (2001) Neutrophils and macrophages accumulate sequentially following Achilles tendon injury. J Orthop Res 19, 1203-1209

8. Kawamura, S., Ying, L., Kim, H. J., Dynybil, C., and Rodeo, S. A. (2005) Macrophages accumulate in the early phase of tendon-bone healing. J Orthop Res 23, 1425-1432

9. Wong, J. K., Lui, Y. H., Kapacee, Z., Kadler, K. E., Ferguson, M. W., and McGrouther, D. A. (2009) The cellular biology of flexor tendon adhesion formation: an old problem in a new paradigm. Am $J$ Pathol 175, 1938-1951

10. Zhao, G., Zhang, J., Nie, D., Zhou, Y., Li, F., Onishi, K., Billiar, T., and Wang, J. H. (2019) HMGB1 mediates the development of tendinopathy due to mechanical overloading. PLoS One 14, e0222369 
554 11. Pingel, J., Wienecke, J., Kongsgaard, M., Behzad, H., Abraham, T., Langberg, H., and Scott, A. (2013)

Increased mast cell numbers in a calcaneal tendon overuse model. Scand J Med Sci Sports 23, e353-360

12. Messner, K., Wei, Y., Andersson, B., Gillquist, J., and Rasanen, T. (1999) Rat model of Achilles tendon disorder. A pilot study. Cells Tissues Organs 165, 30-39

13. Backman, C., Boquist, L., Friden, J., Lorentzon, R., and Toolanen, G. (1990) Chronic achilles paratenonitis with tendinosis: an experimental model in the rabbit. J Orthop Res 8, 541-547

14. Barbe, M. F., Barr, A. E., Gorzelany, I., Amin, M., Gaughan, J. P., and Safadi, F. F. (2003) Chronic repetitive reaching and grasping results in decreased motor performance and widespread tissue responses in a rat model of MSD. J Orthop Res 21, 167-176

15. Kietrys, D. M., Barr-Gillespie, A. E., Amin, M., Wade, C. K., Popoff, S. N., and Barbe, M. F. (2012) Aging contributes to inflammation in upper extremity tendons and declines in forelimb agility in a rat model of upper extremity overuse. PLoS One 7, e46954

16. Fedorczyk, J. M., Barr, A. E., Rani, S., Gao, H. G., Amin, M., Amin, S., Litvin, J., and Barbe, M. F. (2010) Exposure-dependent increases in IL-1beta, substance P, CTGF, and tendinosis in flexor digitorum tendons with upper extremity repetitive strain injury. J Orthop Res 28, 298-307

17. Barbe, M. F., Elliott, M. B., Abdelmagid, S. M., Amin, M., Popoff, S. N., Safadi, F. F., and Barr, A. E. (2008) Serum and tissue cytokines and chemokines increase with repetitive upper extremity tasks. $J$ Orthop Res 26, 1320-1326

18. Abate, M., Silbernagel, K. G., Siljeholm, C., Di Iorio, A., De Amicis, D., Salini, V., Werner, S., and Paganelli, R. (2009) Pathogenesis of tendinopathies: inflammation or degeneration? Arthritis Res Ther 11, 235

19. Mosca, M. J., Rashid, M. S., Snelling, S. J., Kirtley, S., Carr, A. J., and Dakin, S. G. (2018) Trends in the theory that inflammation plays a causal role in tendinopathy: a systematic review and quantitative analysis of published reviews. BMJ Open Sport Exerc Med 4, e000332

20. Khan, K. M., Cook, J. L., Kannus, P., Maffulli, N., and Bonar, S. F. (2002) Time to abandon the "tendinitis" myth. BMJ 324, 626-627 
21. Jomaa, G., Kwan, C. K., Fu, S. C., Ling, S. K., Chan, K. M., Yung, P. S., and Rolf, C. (2020) A systematic review of inflammatory cells and markers in human tendinopathy. BMC Musculoskelet

Disord 21, 78

22. Rees, J. D., Stride, M., and Scott, A. (2014) Tendons--time to revisit inflammation. Br J Sports Med 48, $1553-1557$

23. Gilroy, D. W., and Bishop-Bailey, D. (2019) Lipid mediators in immune regulation and resolution. $B r J$ Pharmacol 176, 1009-1023

24. Leuti, A., Fazio, D., Fava, M., Piccoli, A., Oddi, S., and Maccarrone, M. (2020) Bioactive lipids, inflammation and chronic diseases. Adv Drug Deliv Rev

25. Christie, W. W., and Harwood, J. L. (2020) Oxidation of polyunsaturated fatty acids to produce lipid mediators. Essays Biochem

26. Su, B., and O'Connor, J. P. (2013) NSAID therapy effects on healing of bone, tendon, and the enthesis. $J$ Appl Physiol (1985) 115, 892-899

27. Zhang, J., Middleton, K. K., Fu, F. H., Im, H. J., and Wang, J. H. (2013) HGF mediates the antiinflammatory effects of PRP on injured tendons. PLoS One 8, e67303

28. Zhang, J., Pan, T., and Wang, J. H. (2014) Cryotherapy suppresses tendon inflammation in an animal model. J Orthop Translat 2, 75-81

29. Zhang, J., Pan, T., Liu, Y., and Wang, J. H. (2010) Mouse treadmill running enhances tendons by expanding the pool of tendon stem cells (TSCs) and TSC-related cellular production of collagen. $J$ Orthop Res 28, 1178-1183

30. Langberg, H., Boushel, R., Skovgaard, D., Risum, N., and Kjaer, M. (2003) Cyclo-oxygenase-2 mediated prostaglandin release regulates blood flow in connective tissue during mechanical loading in humans. J Physiol 551, 683-689

31. Langberg, H., Skovgaard, D., Petersen, L. J., Bulow, J., and Kjaer, M. (1999) Type I collagen synthesis and degradation in peritendinous tissue after exercise determined by microdialysis in humans. $J$ Physiol 
32. Zurier, R. B., and Sayadoff, D. M. (1975) Release of prostaglandins from human polymorphonuclear leukocytes. Inflammation 1, 93-101

33. Humes, J. L., Bonney, R. J., Pelus, L., Dahlgren, M. E., Sadowski, S. J., Kuehl, F. A., Jr., and Davies, P. (1977) Macrophages synthesis and release prostaglandins in response to inflammatory stimuli. Nature 269, 149-151

34. Tsuzaki, M., Guyton, G., Garrett, W., Archambault, J. M., Herzog, W., Almekinders, L., Bynum, D., Yang, X., and Banes, A. J. (2003) IL-1 beta induces COX2, MMP-1, -3 and -13, ADAMTS-4, IL-1 beta and IL-6 in human tendon cells. J Orthop Res 21, 256-264

35. Almekinders, L. C., Baynes, A. J., and Bracey, L. W. (1995) An in vitro investigation into the effects of repetitive motion and nonsteroidal antiinflammatory medication on human tendon fibroblasts. $\mathrm{Am} J$ Sports Med 23, 119-123

36. Serhan, C. N. (2011) The resolution of inflammation: the devil in the flask and in the details. FASEB J 25, 1441-1448

37. Serhan, C. N. (2017) Discovery of specialized pro-resolving mediators marks the dawn of resolution physiology and pharmacology. Mol Aspects Med 58, 1-11

38. Serhan, C. N., Hamberg, M., and Samuelsson, B. (1984) Lipoxins: novel series of biologically active compounds formed from arachidonic acid in human leukocytes. Proc Natl Acad Sci US A 81, 53355339

39. Serhan, C. N., Clish, C. B., Brannon, J., Colgan, S. P., Chiang, N., and Gronert, K. (2000) Novel functional sets of lipid-derived mediators with antiinflammatory actions generated from omega-3 fatty acids via cyclooxygenase 2-nonsteroidal antiinflammatory drugs and transcellular processing. $J$ Exp Med 192, 1197-1204

40. Serhan, C. N., Hong, S., Gronert, K., Colgan, S. P., Devchand, P. R., Mirick, G., and Moussignac, R. L. (2002) Resolvins: a family of bioactive products of omega-3 fatty acid transformation circuits initiated by aspirin treatment that counter proinflammation signals. J Exp Med 196, 1025-1037 

available under aCC-BY 4.0 International license.

41. Mukherjee, P. K., Marcheselli, V. L., Serhan, C. N., and Bazan, N. G. (2004) Neuroprotectin D1: a docosahexaenoic acid-derived docosatriene protects human retinal pigment epithelial cells from oxidative stress. Proc Natl Acad Sci U S A 101, 8491-8496

42. Serhan, C. N., Yang, R., Martinod, K., Kasuga, K., Pillai, P. S., Porter, T. F., Oh, S. F., and Spite, M. (2009) Maresins: novel macrophage mediators with potent antiinflammatory and proresolving actions. $J$ Exp Med 206, 15-23

43. Chiang, N., and Serhan, C. N. (2017) Structural elucidation and physiologic functions of specialized pro-resolving mediators and their receptors. Mol Aspects Med 58, 114-129

44. Dalli, J., and Serhan, C. N. (2017) Pro-Resolving Mediators in Regulating and Conferring Macrophage Function. Front Immunol 8, 1400

45. Serhan, C. N. (2017) Treating inflammation and infection in the 21st century: new hints from decoding resolution mediators and mechanisms. FASEB J 31, 1273-1288

46. Dalli, J., and Serhan, C. N. (2019) Identification and structure elucidation of the pro-resolving mediators provides novel leads for resolution pharmacology. Br J Pharmacol 176, 1024-1037

47. Giannakis, N., Sansbury, B. E., Patsalos, A., Hays, T. T., Riley, C. O., Han, X., Spite, M., and Nagy, L. (2019) Dynamic changes to lipid mediators support transitions among macrophage subtypes during muscle regeneration. Nat Immunol 20, 626-636

48. Markworth, J. F., Brown, L. A., Lim, E., Floyd, C., Larouche, J., Castor-Macias, J. A., Sugg, K. B., Sarver, D. C., Macpherson, P. C., Davis, C., Aguilar, C. A., Maddipati, K. R., and Brooks, S. V. (2020) Resolvin D1 supports skeletal myofiber regeneration via actions on myeloid and muscle stem cells. JCI Insight 5

49. Dakin, S. G., Dudhia, J., and Smith, R. K. (2014) Resolving an inflammatory concept: the importance of inflammation and resolution in tendinopathy. Vet Immunol Immunopathol 158, 121-127

50. Dakin, S. G., Dudhia, J., Werling, N. J., Werling, D., Abayasekara, D. R., and Smith, R. K. (2012) Inflamm-aging and arachadonic acid metabolite differences with stage of tendon disease. PLoS One 7, e48978 
657 51. Dakin, S. G., Werling, D., Hibbert, A., Abayasekara, D. R., Young, N. J., Smith, R. K., and Dudhia, J. (2012) Macrophage sub-populations and the lipoxin A4 receptor implicate active inflammation during equine tendon repair. PLoS One 7, e32333

52. Dakin, S. G., Ly, L., Colas, R. A., Oppermann, U., Wheway, K., Watkins, B., Dalli, J., and Carr, A. J. (2017) Increased 15-PGDH expression leads to dysregulated resolution responses in stromal cells from patients with chronic tendinopathy. Sci Rep 7, 11009

53. Dakin, S. G., Colas, R. A., Newton, J., Gwilym, S., Jones, N., Reid, H. A. B., Wood, S., Appleton, L., Wheway, K., Watkins, B., Dalli, J., and Carr, A. J. (2019) 15-Epi-LXA4 and MaR1 counter inflammation in stromal cells from patients with Achilles tendinopathy and rupture. FASEB J 33, 80438054

54. Dakin, S. G., Colas, R. A., Wheway, K., Watkins, B., Appleton, L., Rees, J., Gwilym, S., Little, C., Dalli, J., and Carr, A. J. (2019) Proresolving Mediators LXB4 and RvE1 Regulate Inflammation in Stromal Cells from Patients with Shoulder Tendon Tears. Am J Pathol 189, 2258-2268

55. Dakin, S. G., Martinez, F. O., Yapp, C., Wells, G., Oppermann, U., Dean, B. J., Smith, R. D., Wheway, K., Watkins, B., Roche, L., and Carr, A. J. (2015) Inflammation activation and resolution in human tendon disease. Sci Transl Med 7, 311ra173

56. Goldberg, A. L. (1967) Work-induced growth of skeletal muscle in normal and hypophysectomized rats. Am J Physiol 213, 1193-1198

57. Markworth, J. F., Vella, L., Lingard, B. S., Tull, D. L., Rupasinghe, T. W., Sinclair, A. J., Maddipati, K. R., and Cameron-Smith, D. (2013) Human inflammatory and resolving lipid mediator responses to resistance exercise and ibuprofen treatment. Am J Physiol Regul Integr Comp Physiol 305, R1281-1296

58. Vella, L., Markworth, J. F., Farnfield, M. M., Maddipati, K. R., Russell, A. P., and Cameron-Smith, D. (2019) Intramuscular inflammatory and resolving lipid profile responses to an acute bout of resistance exercise in men. Physiol Rep 7, e14108 
59. Maddipati, K. R., Romero, R., Chaiworapongsa, T., Zhou, S. L., Xu, Z., Tarca, A. L., Kusanovic, J. P., Munoz, H., and Honn, K. V. (2014) Eicosanomic profiling reveals dominance of the epoxygenase pathway in human amniotic fluid at term in spontaneous labor. $F A S E B J \mathbf{2 8}, 4835-4846$

60. Norris, P. C., Skulas-Ray, A. C., Riley, I., Richter, C. K., Kris-Etherton, P. M., Jensen, G. L., Serhan, C. N., and Maddipati, K. R. (2018) Identification of specialized pro-resolving mediator clusters from healthy adults after intravenous low-dose endotoxin and omega-3 supplementation: a methodological validation. Sci Rep 8, 18050

61. Chong, J., Soufan, O., Li, C., Caraus, I., Li, S., Bourque, G., Wishart, D. S., and Xia, J. (2018) MetaboAnalyst 4.0: towards more transparent and integrative metabolomics analysis. Nucleic Acids Res 46, W486-W494

62. Arita, M., Clish, C. B., and Serhan, C. N. (2005) The contributions of aspirin and microbial oxygenase to the biosynthesis of anti-inflammatory resolvins: novel oxygenase products from omega-3 polyunsaturated fatty acids. Biochem Biophys Res Commun 338, 149-157

63. Langberg, H., Skovgaard, D., Karamouzis, M., Bulow, J., and Kjaer, M. (1999) Metabolism and inflammatory mediators in the peritendinous space measured by microdialysis during intermittent isometric exercise in humans. J Physiol 515 ( Pt 3), 919-927

64. Svensson, J., Hamberg, M., and Samuelsson, B. (1976) On the formation and effects of thromboxane A2 in human platelets. Acta Physiol Scand 98, 285-294

65. Pouliot, M., Gilbert, C., Borgeat, P., Poubelle, P. E., Bourgoin, S., Creminon, C., Maclouf, J., McColl, S. R., and Naccache, P. H. (1998) Expression and activity of prostaglandin endoperoxide synthase-2 in agonist-activated human neutrophils. FASEB J 12, 1109-1123

66. Lewis, R. A., Soter, N. A., Diamond, P. T., Austen, K. F., Oates, J. A., and Roberts, L. J., 2nd. (1982) Prostaglandin D2 generation after activation of rat and human mast cells with anti-IgE. J Immunol 129, $1627-1631$

67. Kurland, J. I., and Bockman, R. (1978) Prostaglandin E production by human blood monocytes and mouse peritoneal macrophages. J Exp Med 147, 952-957 
68. Weksler, B. B., Marcus, A. J., and Jaffe, E. A. (1977) Synthesis of prostaglandin I2 (prostacyclin) by cultured human and bovine endothelial cells. Proc Natl Acad Sci U S A 74, 3922-3926

69. Zucali, J. R., Dinarello, C. A., Oblon, D. J., Gross, M. A., Anderson, L., and Weiner, R. S. (1986) Interleukin 1 stimulates fibroblasts to produce granulocyte-macrophage colony-stimulating activity and prostaglandin E2. J Clin Invest 77, 1857-1863

70. Ali, A. E., Barrett, J. C., and Eling, T. E. (1980) Prostaglandin and thromboxane production by fibroblasts and vascular endothelial cells. Adv Prostaglandin Thromboxane Res 6, 533-535

71. Bryant, R. W., Feinmark, S. J., Makheja, A. N., and Bailey, J. M. (1978) Lipid metabolism in cultured cells. Synthesis of vasoactive thromboxane A2 from [14C]arachidonic acid culture lung fibroblasts. $J$ Biol Chem 253, 8134-8142

72. Wang, J. H., Jia, F., Yang, G., Yang, S., Campbell, B. H., Stone, D., and Woo, S. L. (2003) Cyclic mechanical stretching of human tendon fibroblasts increases the production of prostaglandin E2 and levels of cyclooxygenase expression: a novel in vitro model study. Connect Tissue Res 44, 128-133

73. Almekinders, L. C., Banes, A. J., and Ballenger, C. A. (1993) Effects of repetitive motion on human fibroblasts. Med Sci Sports Exerc 25, 603-607

74. Bergqvist, F., Carr, A. J., Wheway, K., Watkins, B., Oppermann, U., Jakobsson, P. J., and Dakin, S. G. (2019) Divergent roles of prostacyclin and PGE2 in human tendinopathy. Arthritis Res Ther 21, 74

75. Fitzpatrick, F. A., and Wynalda, M. A. (1983) Albumin-catalyzed metabolism of prostaglandin D2. Identification of products formed in vitro. J Biol Chem 258, 11713-11718

76. Williams, T. J. (1979) Prostaglandin E2, prostaglandin I2 and the vascular changes of inflammation. $\mathrm{Br}$ J Pharmacol 65, 517-524

77. Rajakariar, R., Hilliard, M., Lawrence, T., Trivedi, S., Colville-Nash, P., Bellingan, G., Fitzgerald, D., Yaqoob, M. M., and Gilroy, D. W. (2007) Hematopoietic prostaglandin D2 synthase controls the onset and resolution of acute inflammation through PGD2 and 15-deoxyDelta12 14 PGJ2. Proc Natl Acad Sci US A 104, 20979-20984 
78. Gilroy, D. W., Colville-Nash, P. R., Willis, D., Chivers, J., Paul-Clark, M. J., and Willoughby, D. A. (1999) Inducible cyclooxygenase may have anti-inflammatory properties. Nat Med 5, 698-701

79. Li, Z., Yang, G., Khan, M., Stone, D., Woo, S. L., and Wang, J. H. (2004) Inflammatory response of human tendon fibroblasts to cyclic mechanical stretching. Am J Sports Med 32, 435-440

80. Werner, M., Jordan, P. M., Romp, E., Czapka, A., Rao, Z., Kretzer, C., Koeberle, A., Garscha, U., Pace, S., Claesson, H. E., Serhan, C. N., Werz, O., and Gerstmeier, J. (2019) Targeting biosynthetic networks of the proinflammatory and proresolving lipid metabolome. FASEB J 33, 6140-6153

81. Serhan, C. N., Hamberg, M., Samuelsson, B., Morris, J., and Wishka, D. G. (1986) On the stereochemistry and biosynthesis of lipoxin B. Proc Natl Acad Sci U S A 83, 1983-1987

82. Serhan, C. N., Nicolaou, K. C., Webber, S. E., Veale, C. A., Dahlen, S. E., Puustinen, T. J., and Samuelsson, B. (1986) Lipoxin A. Stereochemistry and biosynthesis. J Biol Chem 261, 16340-16345

83. Hong, S., Gronert, K., Devchand, P. R., Moussignac, R. L., and Serhan, C. N. (2003) Novel docosatrienes and 17S-resolvins generated from docosahexaenoic acid in murine brain, human blood, and glial cells. Autacoids in anti-inflammation. J Biol Chem 278, 14677-14687

84. Wang, Y., He, G., Tang, H., Shi, Y., Kang, X., Lyu, J., Zhu, M., Zhou, M., Yang, M., Mu, M., Chen, W., Zhou, B., Zhang, J., and Tang, K. (2019) Aspirin inhibits inflammation and scar formation in the injury tendon healing through regulating JNK/STAT-3 signalling pathway. Cell Prolif 52, e12650

85. Lehner, C., Spitzer, G., Gehwolf, R., Wagner, A., Weissenbacher, N., Deininger, C., Emmanuel, K., Wichlas, F., Tempfer, H., and Traweger, A. (2019) Tenophages: a novel macrophage-like tendon cell population expressing CX3CL1 and CX3CR1. Dis Model Mech 12

86. Honda, H., Kimura, H., and Rostami, A. (1990) Demonstration and phenotypic characterization of resident macrophages in rat skeletal muscle. Immunology 70, 272-277

87. Gottfried, E., Kunz-Schughart, L. A., Weber, A., Rehli, M., Peuker, A., Muller, A., Kastenberger, M., Brockhoff, G., Andreesen, R., and Kreutz, M. (2008) Expression of CD68 in non-myeloid cell types. 
bioRxiv preprint doi: https://doi.org/10.1101/2021.01.08.425901; this version posted January 9, 2021. The copyright holder for this preprint (which was not certified by peer review) is the author/funder, who has granted bioRxiv a license to display the preprint in perpetuity. It is made available under aCC-BY 4.0 International license.

757 88. Andersson, G., Backman, L. J., Scott, A., Lorentzon, R., Forsgren, S., and Danielson, P. (2011)

Substance $\mathrm{P}$ accelerates hypercellularity and angiogenesis in tendon tissue and enhances paratendinitis in response to Achilles tendon overuse in a tendinopathy model. Br J Sports Med 45, 1017-1022

89. Chbinou, N., and Frenette, J. (2004) Insulin-dependent diabetes impairs the inflammatory response and delays angiogenesis following Achilles tendon injury. Am J Physiol Regul Integr Comp Physiol 286, R952-957

90. Nieman, D. C., Gillitt, N. D., Chen, G. Y., Zhang, Q., Sakaguchi, C. A., and Stephan, E. H. (2019) Carbohydrate intake attenuates post-exercise plasma levels of cytochrome P450-generated oxylipins. PLoS One 14, e0213676

91. Nieman, D. C., Gillitt, N. D., Chen, G. Y., Zhang, Q., Sha, W., Kay, C. D., Chandra, P., Kay, K. L., and Lila, M. A. (2020) Blueberry and/or Banana Consumption Mitigate Arachidonic, Cytochrome P450 Oxylipin Generation During Recovery From 75-Km Cycling: A Randomized Trial. Front Nutr 7, 121

92. Signini, E. F., Nieman, D. C., Silva, C. D., Sakaguchi, C. A., and Catai, A. M. (2020) Oxylipin Response to Acute and Chronic Exercise: A Systematic Review. Metabolites 10

93. Trappe, T. A., Carroll, C. C., Jemiolo, B., Trappe, S. W., Dossing, S., Kjaer, M., and Magnusson, S. P. (2008) Cyclooxygenase mRNA expression in human patellar tendon at rest and after exercise. $\mathrm{Am} \mathrm{J}$ Physiol Regul Integr Comp Physiol 294, R192-199

94. McLennan, I. S., and Macdonald, R. E. (1991) Prostaglandin synthetase and prostacyclin synthetase in mature rat skeletal muscles: immunohistochemical localisation to arterioles, tendons and connective tissues. J Anat 178, 243-253 
Figure Legends:

Figure 1. Divergent lipid mediator profiles of functionally related musculoskeletal tissues. A: Complete profile of lipid mediators detected by tandem liquid chromatography-mass spectrometry (LC-MS/MS) analysis of plantaris tendon homogenates from healthy rats undergoing habitual cage activity ranked by absolute concentration. B: Unsupervised principle component analysis (PCA) score plots of the overall LC-MS/MS profile of functionally associated plantaris tendon and muscle samples. C: PCA loading plot showing the relative contributions of some representative analytes from each major enzymatic biosynthetic pathway. D: Percentage composition of the overall mediator lipidome of plantaris muscle samples. E: Percentage composition of the overall mediator lipidome of plantaris tendon samples. D-E: Linoleic acid (18:2n-6) metabolites (e.g. HODEs \& EpOMEs) are excluded from graphical presentation and are shown in Supplemental Table 1. F: Volcano plot showing the direction, magnitude, and statistical significance of lipid mediator concentrations between tendon and muscle. Each dot represents a single analyte, positive $\log _{2}$ fold changes (FC) indicate lipid mediator concentrations which were enriched in tendon, and negative $\log _{2} \mathrm{FC}$ indicate those enriched in muscle. Analytes with +1.5 absolute $\mathrm{FC}\left(+0.58 \log _{2} \mathrm{FC}\right)$ or $-1.5 \mathrm{FC}\left(-0.58 \log _{2} \mathrm{FC}\right)$ between tissue type and unadjusted $\mathrm{p}<0.05$ were considered to differ significantly between tendon and muscle samples. P-values were determined by twotailed unpaired t-tests. 
Figure 2. Dynamic changes in lipid mediators in response to tendon overuse. Changes in intratendinous

concentrations of each individually detected lipid mediator species in overloaded plantaris tendons when compared to plantaris tendons obtained from ambulatory control rats at (A) day 3, (B) day 7, and (C) day 28 of recovery from synergist ablation-induced plantaris tendon overuse. D: Kinetics of changes in pooled lipid mediator concentration in the overloaded plantaris tendon over the time-course of recovery from synergist ablation surgery. E: Kinetics of changes in intratendinous concentrations of the top 25 individual lipid mediator species modulated by tendon overuse. The data for the full panel of analytes monitored by the LC-MS/MS assay is shown in Supplemental Table 1. F: Changes in the relative contribution of major biosynthetic pathways to the overall tendon mediator lipidome following synergist ablation induced-tendon overuse. D-F: Linoleic acid (18:2n-6) metabolites (e.g. HODEs \& EpOMEs) are excluded from graphical presentation and are shown in Supplemental Table 1. P-values were determined by two-tailed unpaired t-tests (panel A-C) or one-way ANOVA followed by Holm-Šidák post hoc tests (panel D). 
Figure 3. Peritendinous infiltration of inflammatory cells in response to synergist ablation-induced tendon

overuse. A: Mechanically overloaded plantaris tendons were collected from Sprague Dawley rats at day 3, 7, and

28 following synergist ablation surgery. Plantaris tendons from ambulatory age and gender matched rats served as non-surgical controls. Tissue cross-sections were cut from the tendon mid-substance and stained with antibodies against polymorphonuclear cells (PMNs, HIS48 ${ }^{+}$), inflammatory ED1 monocytes/macrophages (MФ,

$\mathrm{CD}^{+} 8^{+}$, and resident/M2-like $\mathrm{ED} 2 \mathrm{M} \Phi\left(\mathrm{CD} 163^{+}\right)$. Images were captured from the periphery of control plantaris tendons (epitenon region), or from within the center of the expanded peritendinous tissue layer at the periphery of overloaded plantaris tendons (neotendon matrix). Quantification of peritendinous infiltration of (B) PMNs

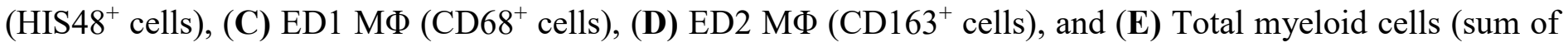
PMNs, ED1 M $\Phi$ and ED2 M ). Values are mean \pm SEM of 5-7 plantaris tendon per time-point with dots representing data from each individual tendon. P-values were determined by one-way ANOVA followed by Holm-Šidák post hoc tests. The original tendon (OT) is traced with a dotted white line. 
bioRxiv preprint doi: https://doi.org/10.1101/2021.01.08.425901; this version posted January 9, 2021. The copyright holder for this preprint (which was not certified by peer review) is the author/funder, who has granted bioRxiv a license to display the preprint in perpetuity. It is made available under aCC-BY 4.0 International license.

851 Figure 4. Inflammatory macrophage infiltration of the original tendon core following plantaris overuse. A:

852 Mechanically overloaded plantaris tendons were collected from Sprague Dawley rats at day 3, 7, and 28 following 853 synergist ablation-induced tendon overuse. Plantaris tendons from ambulatory age and gender matched rats served 854 as non-surgical controls. Tissue cross-sections were cut from the tendon mid-substance and stained with 855 antibodies against polymorphonuclear cells (PMNs, HIS48 ${ }^{+}$cells), inflammatory ED1 monocytes/macrophages

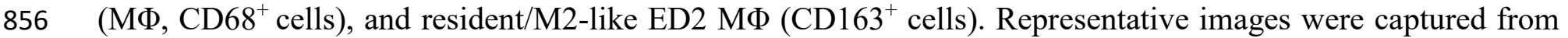
857 the center of the dense original tendon core. 
Figure 5: Local expression of inflammation-related genes in response to synergist ablation-induced

plantaris tendon overuse. Mechanically overloaded plantaris tendons were collected from male Sprague Dawley

rats at day 3,7 , and 28 following synergist ablation surgery. Habitually loaded plantaris tendons from ambulatory age and gender matched rats served as non-surgical controls. Total tendon RNA was extracted, reverse transcribed to cDNA, and expression of inflammation-related genes measured by real-time quantitative reverse transcription PCR (RT-qPCR). Relative mRNA expression (fold change from control) was determined for (A) CD11b (Itgam),

(B) CD68 (Cd68), (C) EMR1 (rat analog of F4/80, Adgre1), (D) CD163 (Cd163), (E) CD206 (Mrc1), (F)

cyclooxygenase-1 (COX-1, Ptgs 1), and (G) cyclooxygenase-2 (COX-2, Ptgs2). Beta-2-Microglobulin (B2m) served as an endogenous control for normalization of genes of interest. Bars show the mean \pm SEM of 8-12 882 plantaris tendons from 4-6 rats per group with dots representing data from each individual tendon sample. Pvalues were determined by one-way ANOVA followed by Holm-Šidák post hoc tests. 
bioRxiv preprint doi: https://doi.org/10.1101/2021.01.08.425901; this version posted January 9, 2021. The copyright holder for this preprint (which was not certified by peer review) is the author/funder, who has granted bioRxiv a license to display the preprint in perpetuity. It is made available under aCC-BY 4.0 International license.

A

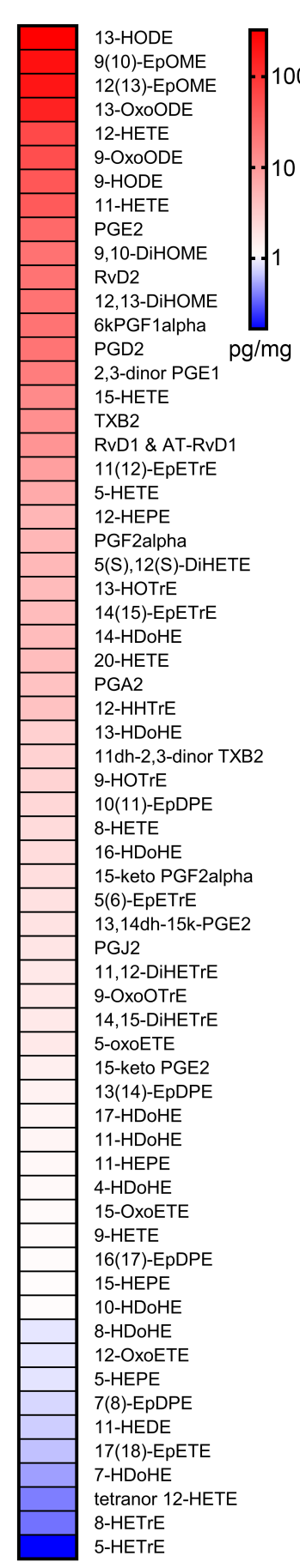

B

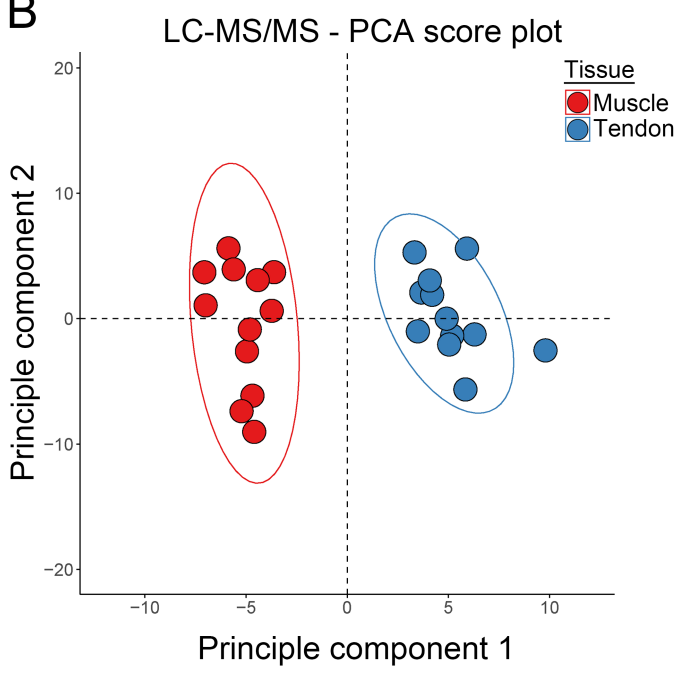

D

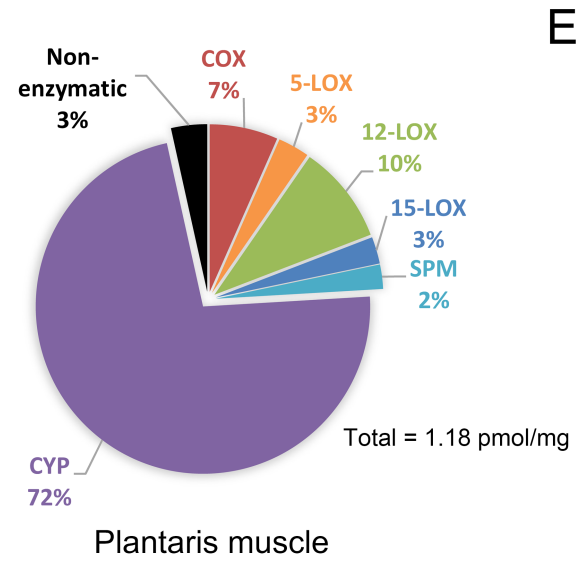

$E$
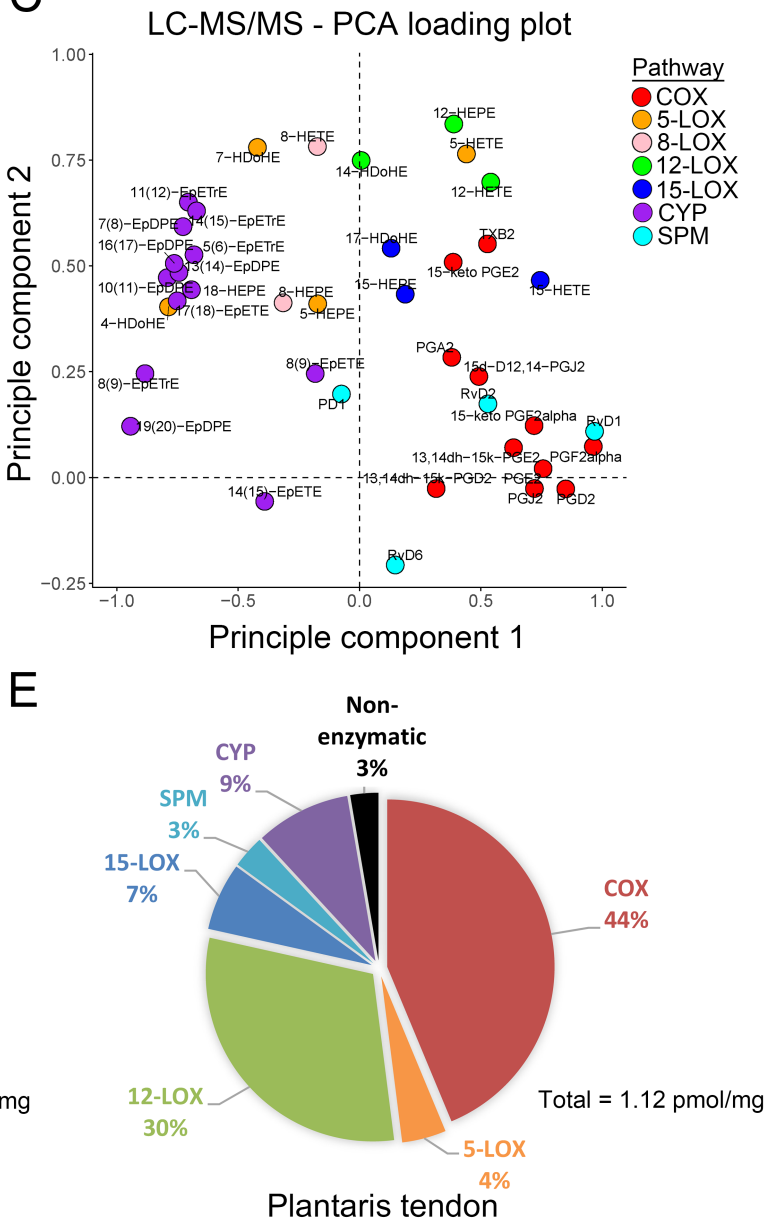

LC-MS/MS - Volcano plot

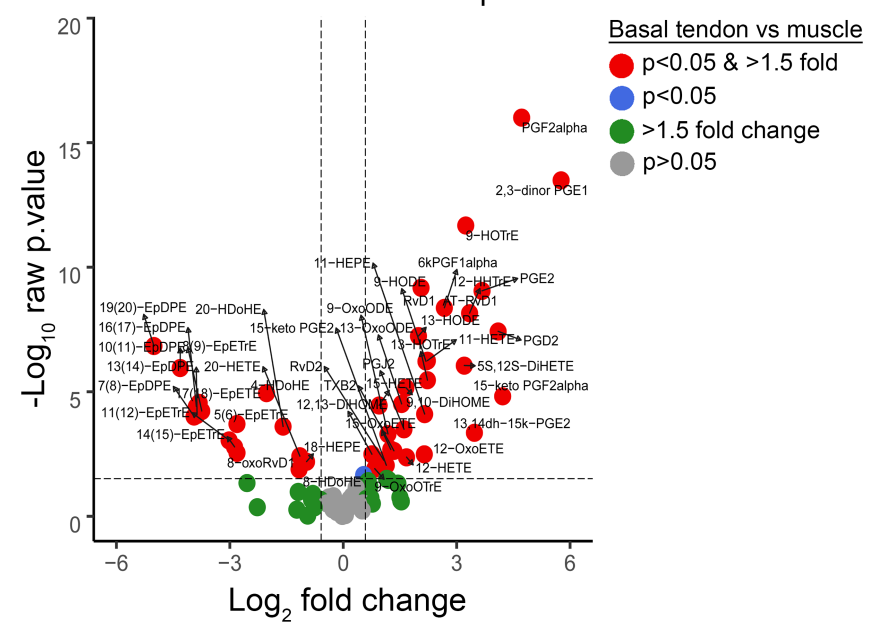

Figure 1. Divergent lipid mediator profiles of functionally related musculoskeletal tissues. A: Complete profile of lipid mediators detected by tandem liquid chromatography-mass spectrometry (LC-MS/MS) analysis of plantaris tendon homogenates from healthy rats undergoing habitual cage activity ranked by absolute concentration. B: Unsupervised principle component analysis (PCA) score plots of the overall LC-MS/MS profile of functionally associated plantaris tendon and muscle samples. C: PCA loading plot showing the relative contributions of some representative analytes from each major enzymatic biosynthetic pathway. D: Percentage composition of the overall mediator lipidome of plantaris muscle samples. E: Percentage composition of the overall mediator lipidome of plantaris tendon samples. D-E: Linoleic acid (18:2n-6) metabolites (e.g. HODEs \& EpOMEs) are excluded from graphical presentation and are shown in Supplemental Table 1. F: Volcano plot showing the direction, magnitude, and statistical significance of lipid mediator concentrations between tendon and muscle. Each dot represents a single analyte, positive $\log _{2}$ fold changes (FC) indicate lipid mediator concentrations which were enriched in tendon, and negative $\log _{2} \mathrm{FC}$ indicate those enriched in muscle. Analytes with +1.5 absolute $\mathrm{FC}$ $\left(+0.58 \log _{2} \mathrm{FC}\right)$ or $-1.5 \mathrm{FC}\left(-0.58 \log _{2} \mathrm{FC}\right)$ between tissue type and unadjusted $\mathrm{p}<0.05$ were considered to differ significantly between tendon and muscle samples. P-values were determined by two-tailed unpaired t-tests. 
bioRxiv preprint doi: https://doi.org/10.1101/2021.01.08.425901; this version posted January 9, 2021. The copyright holder for this preprint (which was not certified by peer review) is the author/funder, who has granted bioRxiv a license to display the preprint in perpetuity. It is made available under aCC-BY 4.0 International license.

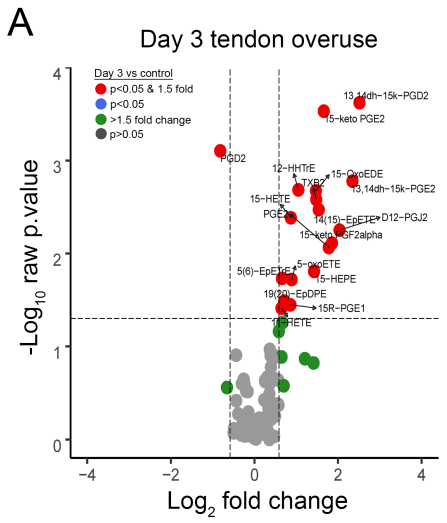

A

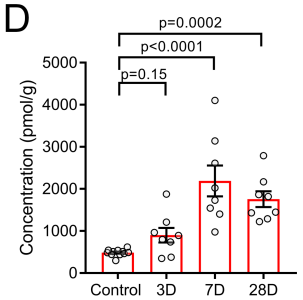

COX pathway
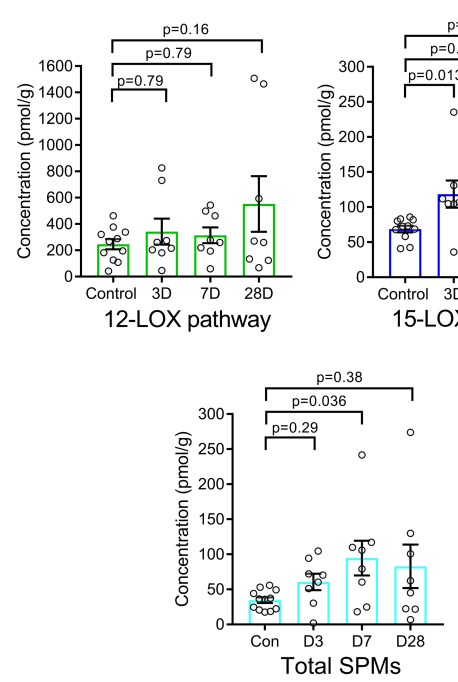

$\mathrm{F}$

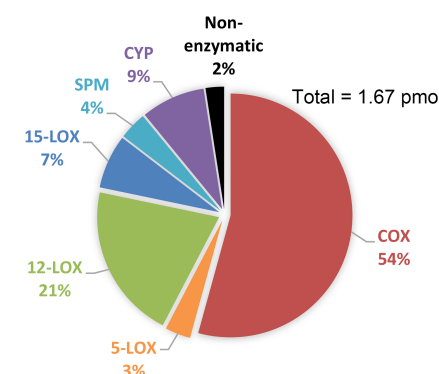

Day 3 tendon overuse
B
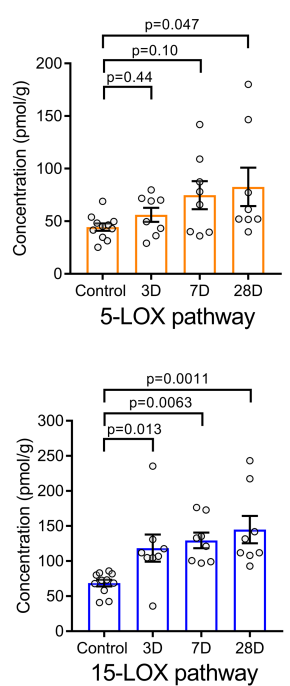

Day 7 tendon overuse

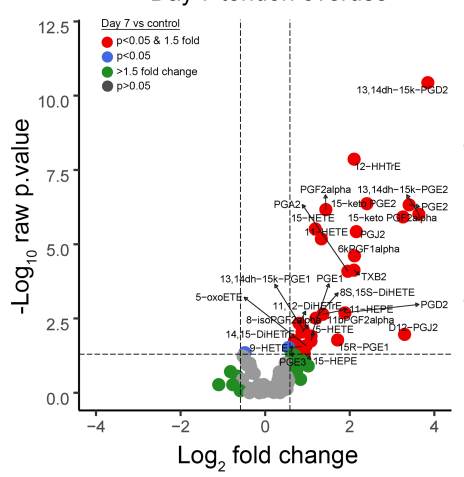

C

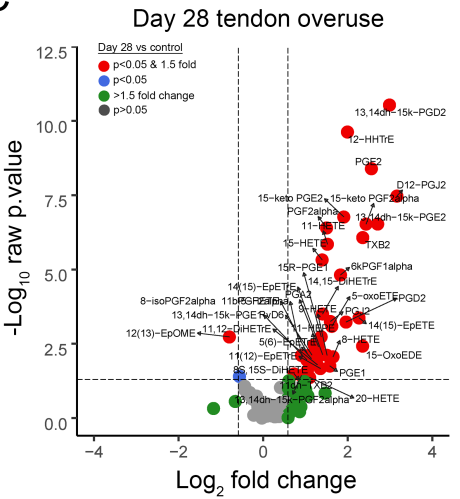

E

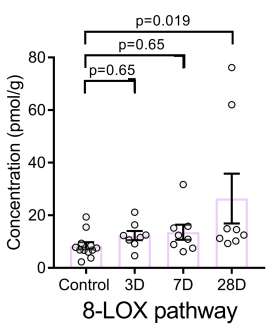

LC-MS/MS - Top 25 tendon lipid mediators
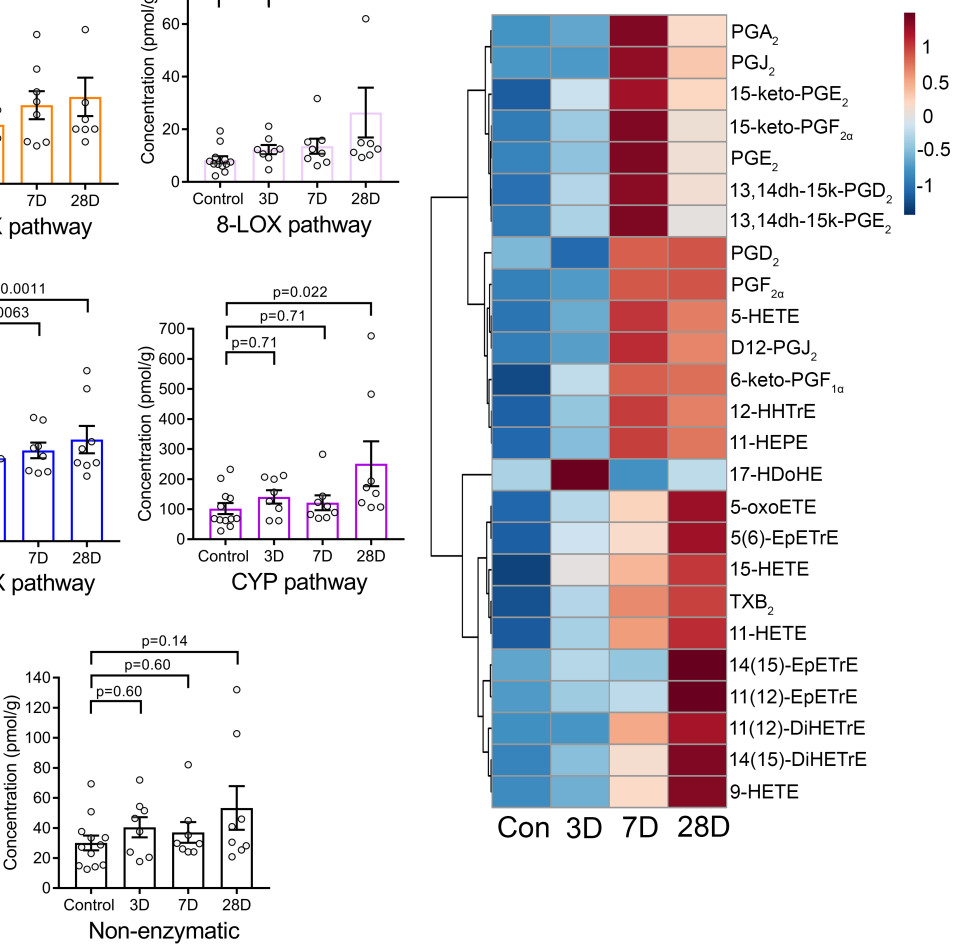

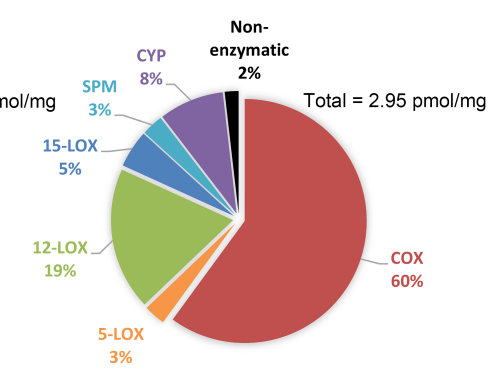

Day 28 tendon overuse

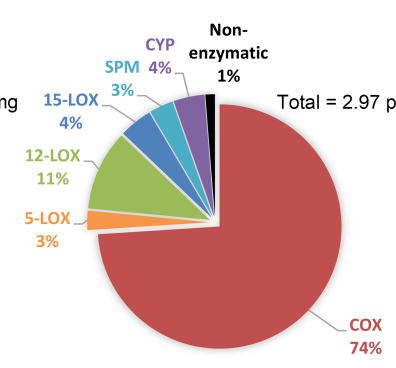

Day 7 tendon overuse

Figure 2. Dynamic changes in lipid mediators in response to tendon overuse. Changes in intratendinous concentrations of each individually detected lipid mediator species in overloaded plantaris tendons when compared to plantaris tendons obtained from ambulatory control rats at (A) day 3, (B) day 7, and (C) day 28 of recovery from synergist ablation-induced plantaris tendon overuse. D: Kinetics of changes in pooled lipid mediator concentration in the overloaded plantaris tendon over the time-course of recovery from synergist ablation surgery. E: Kinetics of changes in intratendinous concentrations of the top 25 individual lipid mediator species modulated by tendon overuse. The data for the full panel of analytes monitored by the LC-MS/MS assay is shown in Supplemental Table 1. F: Changes in the relative contribution of major biosynthetic pathways to the overall tendon mediator lipidome following synergist ablation induced-tendon overuse. D-F: Linoleic acid (18:2n-6) metabolites (e.g. HODEs \& EpOMEs) are excluded from graphical presentation and are shown in Supplemental Table 1. P-values were determined by two-tailed unpaired t-tests (panel A-C) or one-way ANOVA followed by Holm-Šidák post hoc tests (panel D). 
bioRxiv preprint doi: https://doi.org/10.1101/2021.01.08.425901; this version posted January 9, 2021. The copyright holder for this preprint (which was not certified by peer review) is the author/funder, who has granted bioRxiv a license to display the preprint in perpetuity. It is made available under aCC-BY 4.0 International license.

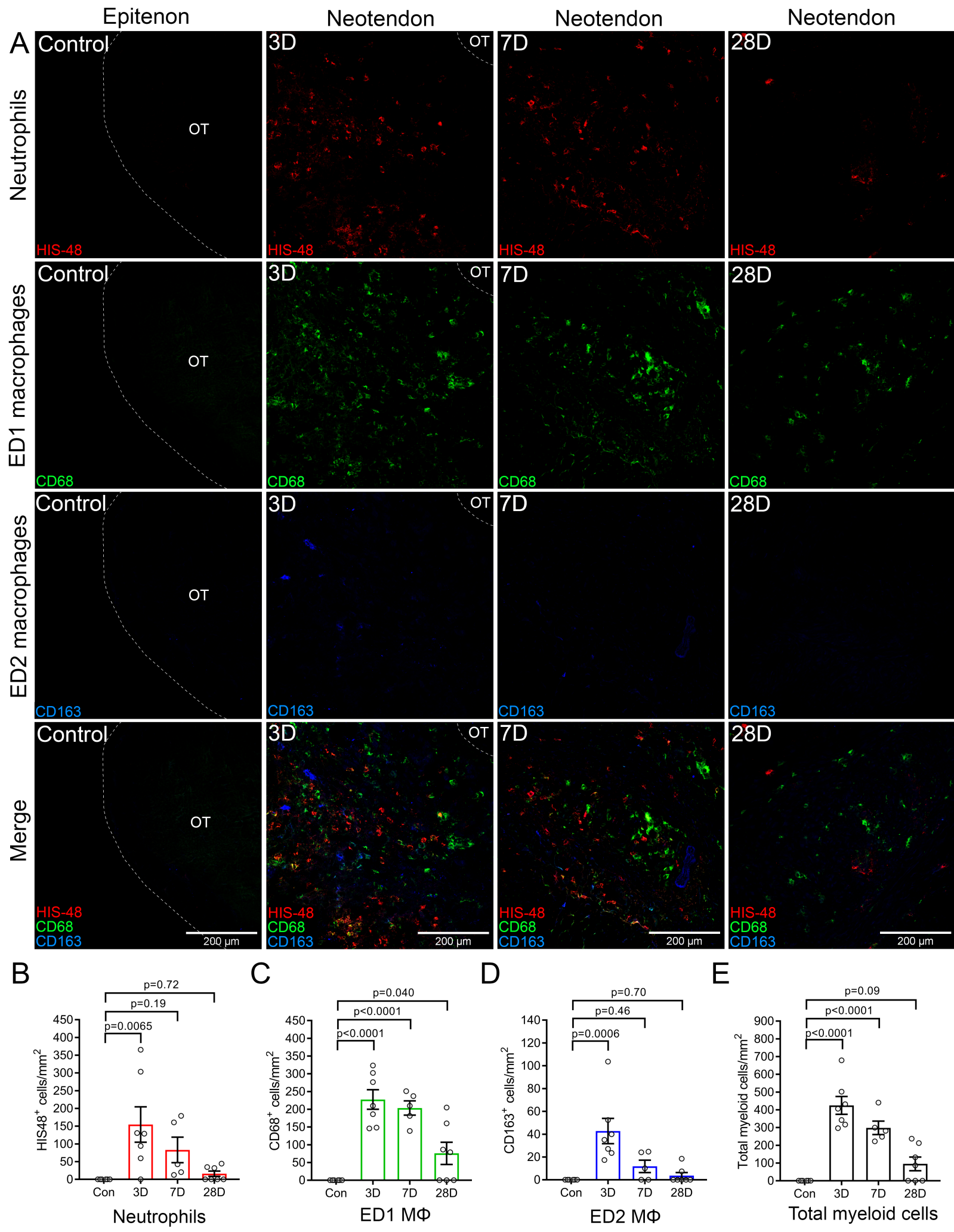

Figure 3. Peritendinous infiltration of inflammatory cells in response to synergist ablation-induced tendon overuse. A: Mechanically overloaded plantaris tendons were collected from Sprague Dawley rats at day 3, 7, and 28 following synergist ablation surgery. Plantaris tendons from ambulatory age and gender matched rats served as non-surgical controls. Tissue cross-sections were cut from the tendon mid-substance and stained with antibodies against polymorphonuclear cells (PMNs, HIS48 ${ }^{+}$), inflammatory ED1 monocytes/macrophages (MФ, $\left.\mathrm{CD} 68^{+}\right)$, and resident/M2-like ED2 $\mathrm{M} \Phi\left(\mathrm{CD} 163^{+}\right)$. Images were captured from the periphery of control plantaris tendons (epitenon region), or from within the center of the expanded peritendinous tissue layer at the periphery of overloaded plantaris tendons (neotendon matrix). Quantification of peritendinous infiltration of (B) PMNs (HIS48 ${ }^{+}$cells), (C) ED1 M $\Phi\left(C D 68^{+}\right.$

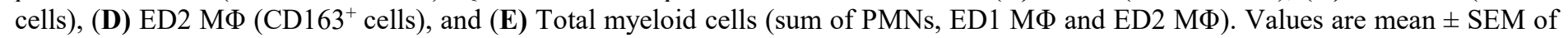
5-7 plantaris tendon per time-point with dots representing data from each individual tendon. P-values were determined by one-way ANOVA followed by Holm-Šidák post hoc tests. The original tendon (OT) is traced with a dotted white line. 
bioRxiv preprint doi: https://doi.org/10.1101/2021.01.08.425901; this version posted January 9, 2021. The copyright holder for this preprint (which was not certified by peer review) is the author/funder, who has granted bioRxiv a license to display the preprint in perpetuity. It is made available under aCC-BY 4.0 International license.

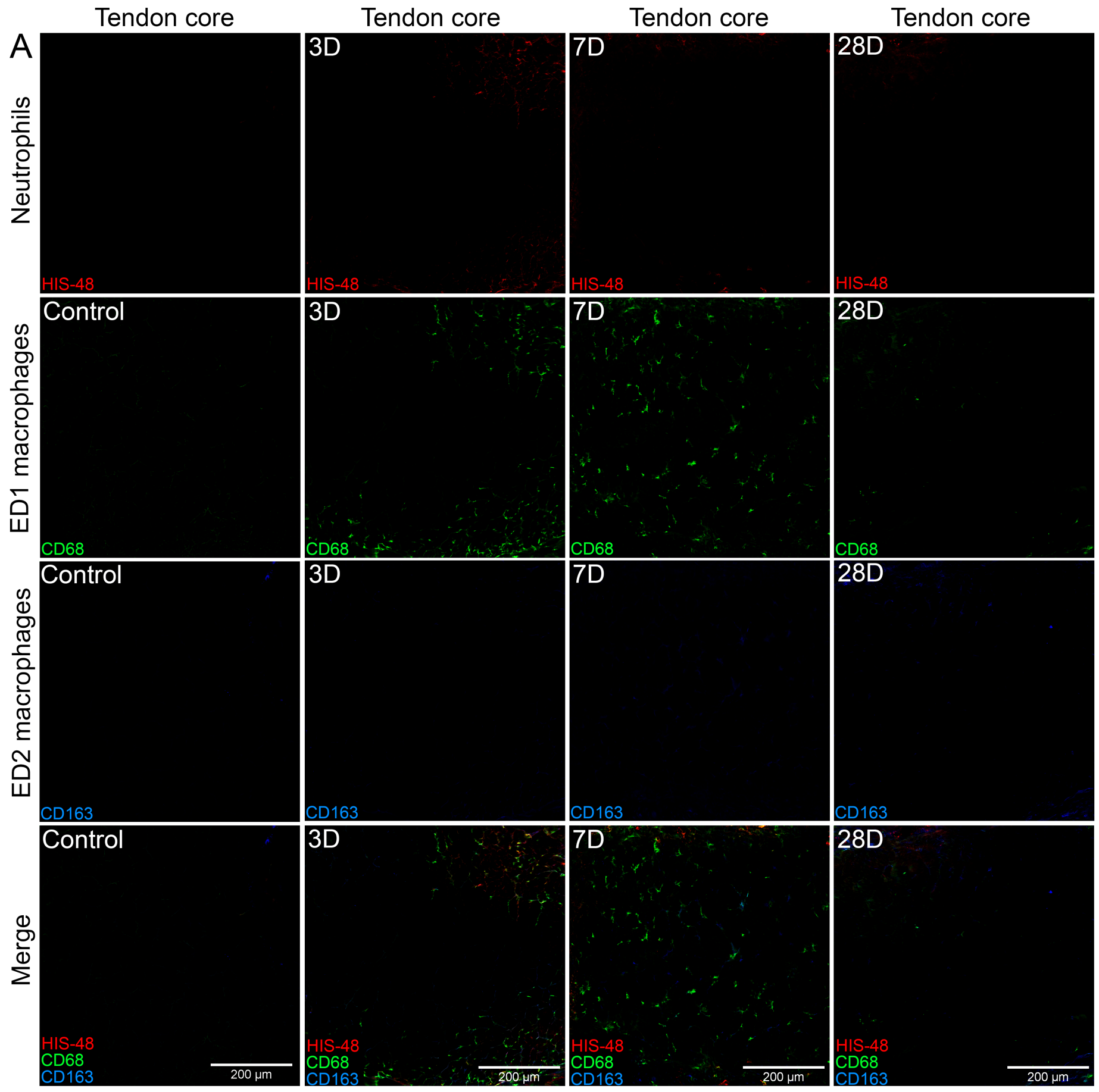

Figure 4. Inflammatory macrophage infiltration of the original tendon core following plantaris overuse. A: Mechanically overloaded plantaris tendons were collected from Sprague Dawley rats at day 3, 7, and 28 following synergist ablation-induced tendon overuse. Plantaris tendons from ambulatory age and gender matched rats served as non-surgical controls. Tissue cross-sections were cut from the tendon mid-substance and stained with antibodies against polymorphonuclear cells (PMNs, HIS48 ${ }^{+}$cells), inflammatory ED1 monocytes/macrophages (MФ, CD68 ${ }^{+}$cells), and resident/M2-like ED2 M $\Phi\left(\mathrm{CD} 163^{+}\right.$cells). Representative images were captured from the center of the dense original tendon core. 
bioRxiv preprint doi: https://doi.org/10.1101/2021.01.08.425901; this version posted January 9,2021 . The copyright holder for this preprint (which was not certified by peer review) is the author/funder, who has granted bioRxiv a license to display the preprint in perpetuity. It is made available under aCC-BY 4.0 International license.
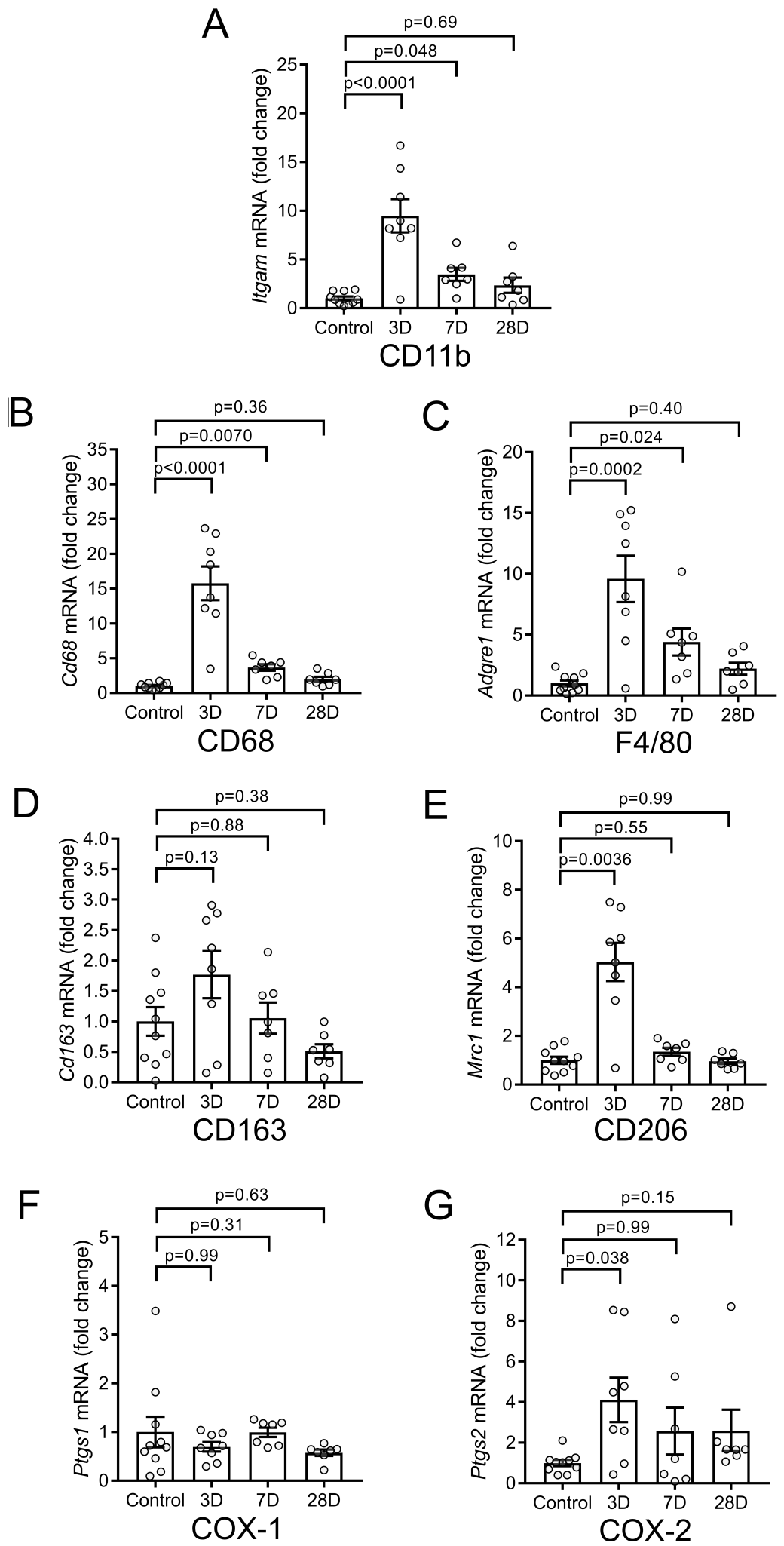

Figure 5: Local expression of inflammation-related genes in response to synergist ablation-induced plantaris tendon overuse. Mechanically overloaded plantaris tendons were collected from male Sprague Dawley rats at day 3, 7, and 28 following synergist ablation surgery. Habitually loaded plantaris tendons from ambulatory age and gender matched rats served as non-surgical controls. Total tendon RNA was extracted, reverse transcribed to cDNA, and expression of inflammation-related genes measured by real-time quantitative reverse transcription PCR (RT-qPCR). Relative mRNA expression (fold change from control) was determined for (A) CD11b (Itgam), (B) CD68 (Cd68), (C) EMR1 (rat analog of F4/80, Adgre1), (D) CD163 (Cd163), (E) CD206 (Mrc1), (F) cyclooxygenase-1 (COX-1, Ptgs 1), and (G) cyclooxygenase-2 (COX-2, Ptgs2). Beta-2-Microglobulin (B2m) served as an endogenous control for normalization of genes of interest. Bars show the mean \pm SEM of 8-12 plantaris tendons from 4-6 rats per group with dots representing data from each individual tendon sample. P-values were determined by one-way ANOVA followed by Holm-Šidák post hoc tests. 
bioRxiv preprint doi: https://doi org/10.1101/2021.01.08.425901. this version posted January 92021 . The copyright holder for this preprint (which was not certified by peer review) is the author/funder, who has granted bioRxiv a license to display the preprint in perpetuity. It is made available under aCC-BY 4.0 International license.

Table 1: Real-time reverse transcription $\mathrm{PCR}$ primers

\begin{tabular}{lll}
\hline Gene & & Sequence \\
\hline Itgam & $\mathrm{F}$ & TGTACCACTCATTGTGGGCA \\
& $\mathrm{R}$ & AGCCAAGCTTGTATAGGCCAG \\
Cd68 & $\mathrm{F}$ & TCCAGCAATTCACCTGGACC \\
& $\mathrm{R}$ & AAGAGAAGCATGGCCCGAAG \\
Adgre1 & $\mathrm{F}$ & CTTCTGGGGAGCTTACAATGG \\
& $\mathrm{R}$ & TGTGGTTCTGAACTGCACGA \\
cd163 & $\mathrm{F}$ & CTGAAATCCTCGGGTTGGCA \\
& $\mathrm{R}$ & TGTAGCTGTGGTCATCCGTG \\
Mrc1 & $\mathrm{F}$ & TCAACTCTTGGACTCACGGC \\
& $\mathrm{R}$ & ATGATCTGCGACTCCGACAC \\
Ptgs1 & $\mathrm{F}$ & AGTACCAGGTGCTGGATGGAGA \\
& $\mathrm{R}$ & GGAGCAACCCAAACACCTCC \\
Ptgs2 & $\mathrm{F}$ & ACGTGTTGACGTCCAGATCA \\
& $\mathrm{R}$ & GGCCCTGGTGTAGTAGGAGA \\
B2m & $\mathrm{F}$ & CACTGAATTCACACCCACCG \\
& $\mathrm{R}$ & TTACATGTCTCGGTCCCAGG
\end{tabular}


bioRxiv preprint doi: https://doi.org/10.1101/2021.01.08.425901; this version posted January 9,2021 . The copyright holder for this preprint (which was not certified by peer review) is the author/funder, who has granted bioRxiv a license to display the preprint in perpetuity. It is made available under aCC-BY 4.0 International license.

\begin{tabular}{|c|c|c|c|c|c|c|c|}
\hline & Control & Day 3 & & Day 7 & & Day 28 & \\
\hline Tendon mass (mg) & $14.76 \pm 1.23$ & $13.36 \pm 2.09$ & & $25.95 \pm 6.89$ & & $32.60 \pm 7.70$ & * \\
\hline RNA concentration (ng/mg) & $65.91 \pm 7.80$ & $239.38 \pm 17.48$ & $* * *$ & $165.81 \pm 19.84$ & $* \star *$ & $105.21 \pm 11.67$ & \\
\hline Total RNA content $(\mu \mathrm{g})$ & $0.94 \pm 0.11$ & $3.26 \pm 0.55$ & ** & $3.74 \pm 0.75$ & $* * *$ & $3.31 \pm 0.70$ & ** \\
\hline
\end{tabular}

Values are mean \pm SEM of $8-12$ plantaris tendons from $4-6$ rats/group. ${ }^{*} p<0.05,{ }^{* *} p<0.01,{ }^{* * *} p<0.001$ vs. control 
bioRxiv preprint doi: https://doi.org/10.1101/2021.01.08.425901; this version posted January 9, 2021. The copyright holder for this preprint (which was not certified by peer review) is the author/funder, who has granted bioRxiv a license to display the preprint in perpetuity. It is made available under aCC-BY 4.0 International license.

Supplemental Table 1A: Cyclooxygenase (COX) metabolite concentration (pmol/g) in overloaded rat plantaris tendons

\begin{tabular}{|c|c|c|c|c|c|c|}
\hline Pathway & Substrate & Analyte & Control & Day 3 overload & Day 7 overload & Day 28 overload \\
\hline \multirow{44}{*}{$\begin{array}{l}0 \\
0 \\
0 \\
0 \\
0 \\
0 \\
0 \\
0 \\
0 \\
0\end{array}$} & $20: 3 n-6$ & PGE1 & ND & ND & $5.97 \pm 2.54$ & $7.20 \pm 3.63$ \\
\hline & $20: 3 n-6$ & PGF1a & ND & ND & ND & ND \\
\hline & $20: 3 n-6$ & 15-keto PGE1 & ND & ND & ND & ND \\
\hline & $20: 3 n-6$ & 13,14dhPGE1 & ND & ND & $1.72 \pm 1.07$ & ND \\
\hline & $20: 3 n-6$ & D17-PGE1 & ND & ND & ND & ND \\
\hline & $20: 3 n-6$ & Bicyclo PGE1 & ND & ND & ND & ND \\
\hline & $20: 3 n-6$ & 6-keto PGE1 & ND & ND & ND & ND \\
\hline & $20: 3 n-6$ & 2,3-dinor PGE1 & $64.87 \pm 9.10$ & $69.00 \pm 11.35$ & $83.49 \pm 27.00$ & $55.29 \pm 24.36$ \\
\hline & $20: 3 n-6$ & 19(R)-hydroxy PGE1 & ND & ND & ND & ND \\
\hline & $20: 3 n-6$ & 15(R)-PGE1 & ND & ND & $6.24 \pm 3.03$ & $3.38 \pm 0.00$ \\
\hline & $20: 4 n-6$ & TXB2 & $35.99 \pm 4.39$ & $100.40 \pm 20.67$ & $154.67 \pm 28.48$ & $184.42 \pm 25.55$ \\
\hline & $20: 4 n-6$ & 12-HHTrE & $13.26 \pm 0.82$ & $27.49 \pm 4.57$ & $57.07 \pm 7.58$ & $52.89 \pm 5.12$ \\
\hline & $20: 4 n-6$ & PGD2 & $56.40 \pm 5.13$ & $30.31 \pm 4.76$ & $208.69 \pm 64.00$ & $219.80 \pm 60.36$ \\
\hline & $20: 4 n-6$ & PGE2 & $75.09 \pm 6.70$ & $257.97 \pm 79.88$ & $796.02 \pm 245.10$ & $443.39 \pm 69.52$ \\
\hline & $20: 4 n-6$ & PGF2a & $13.48 \pm 1.26$ & $17.28 \pm 2.54$ & $36.48 \pm 3.94$ & $38.20 \pm 3.77$ \\
\hline & $20: 4 n-6$ & 6kPGF1a & $63.77 \pm 8.77$ & $100.08 \pm 21.80$ & $275.82 \pm 54.00$ & $226.97 \pm 34.45$ \\
\hline & $20: 4 n-6$ & PGJ2 & $5.00 \pm 0.59$ & $5.36 \pm 0.72$ & $22.28 \pm 4.43$ & $15.07 \pm 3.57$ \\
\hline & $20: 4 n-6$ & PGA2 & $9.20 \pm 1.85$ & $11.90 \pm 2.45$ & $37.64 \pm 6.22$ & $24.02 \pm 4.88$ \\
\hline & $20: 4 n-6$ & 15-keto PGE2 & $3.55 \pm 0.43$ & $11.64 \pm 2.12$ & $19.54 \pm 3.56$ & $13.83 \pm 1.68$ \\
\hline & $20: 4 n-6$ & 15-keto PGF2a & $4.26 \pm 0.70$ & $16.23 \pm 4.42$ & $43.51 \pm 3.56$ & $24.55 \pm 1.68$ \\
\hline & $20: 4 n-6$ & 13,14dh-15k-PGE2 & $2.83 \pm 4.08$ & $16.68 \pm 4.72$ & $41.22 \pm 11.59$ & $21.71 \pm 3.21$ \\
\hline & $20: 4 n-6$ & 13,14dh-15k-PGD2 & ND & $11.75 \pm 3.75$ & $30.80 \pm 5.74$ & $16.98 \pm 2.39$ \\
\hline & $20: 4 n-6$ & 13,14dh-15k-PGF2a & ND & ND & $2.15 \pm 1.02$ & $1.25 \pm 0.62$ \\
\hline & $20: 4 n-6$ & 11dh-2,3-dinor TXB2 & $3.38 \pm 1.37$ & $3.51 \pm 1.41$ & $4.44 \pm 2.75$ & $6.57 \pm 4.19$ \\
\hline & $20: 4 n-6$ & 11-HETE & $128.80 \pm 12.51$ & $201.81 \pm 33.16$ & $324.08 \pm 30.75$ & $369.95 \pm 41.71$ \\
\hline & $20: 4 n-6$ & Bicyclo PGE2 & ND & $1.89 \pm 0.46$ & $2.55 \pm 0.79$ & $1.17 \pm 0.38$ \\
\hline & $20: 4 n-6$ & D12-PGJ2 & ND & $5.41 \pm 1.96$ & $15.29 \pm 7.01$ & $14.59 \pm 3.42$ \\
\hline & $20: 4 n-6$ & 15d-D12,14-PGJ2 & ND & ND & $1.31 \pm 0.67$ & ND \\
\hline & $20: 4 n-6$ & 8-isoPGF2a \& 11bPGF2a & ND & ND & $1.54 \pm 0.59$ & $1.31 \pm 0.48$ \\
\hline & $20: 4 n-6$ & 19(R)-OH PGF2a \& 20-OH PGF2a & ND & ND & ND & ND \\
\hline & $20: 4 n-6$ & 19(R)-OH PGE2 \& 20-OH PGE2 & ND & ND & ND & ND \\
\hline & $20: 4 n-6$ & 2,3-dinor TXB2 & ND & ND & ND & ND \\
\hline & $20: 4 n-6$ & 11dh-TXB2 & ND & ND & ND & ND \\
\hline & $20: 4 n-6$ & tetranor PGEM & ND & ND & ND & ND \\
\hline & $20: 4 n-6$ & 6,15-diketo PGFa & ND & ND & ND & ND \\
\hline & $20: 4 n-6$ & iPF-VI & ND & ND & ND & ND \\
\hline & $20: 5 n-3$ & TXB3 & ND & ND & $2.03 \pm 0.96$ & $1.49 \pm 0.50$ \\
\hline & $20: 5 n-3$ & PGD3 & ND & ND & ND & ND \\
\hline & $20: 5 n-3$ & PGE3 & ND & ND & $5.83 \pm 2.84$ & ND \\
\hline & $20: 5 n-3$ & PGF3a & ND & ND & ND & ND \\
\hline & $20: 5 n-3$ & 11dh TXB3 & ND & ND & ND & ND \\
\hline & $20: 5 n-3$ & 15d-D12,14-PGJ3 & ND & ND & ND & ND \\
\hline & $20: 5 n-3$ & 11-HEPE & $3.01 \pm 0.78$ & $3.72 \pm 1.55$ & $8.44 \pm 1.60$ & $7.57 \pm 1.23$ \\
\hline & & Sum & $486.40 \pm 24.18$ & $900.70 \pm 172.54$ & $2190.70 \pm 365.80$ & $1754.76 \pm 187.05$ \\
\hline
\end{tabular}

Values are mean \pm SEM of 8-12 tendons from 4-6 rats/group. ND = Below limits of detection of the assay. 
bioRxiv preprint doi: https://doi.org/10.1101/2021.01.08.425901; this version posted January 9, 2021. The copyright holder for this preprint (which was not certified by peer review) is the author/funder, who has granted bioRxiv a license to display the preprint in perpetuity. It is made available under aCC-BY 4.0 International license.

Supplemental Table 1B: Lipoxygenase (LOX) metabolite concentration (pmol/g) in overloaded rat plantaris tendons

\begin{tabular}{|c|c|c|c|c|c|c|}
\hline Pathway & Substrate & Analyte & Control & Day 3 overload & Day 7 overload & Day 28 overload \\
\hline \multirow{11}{*}{ 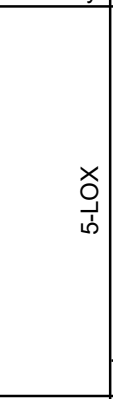 } & $18: 3 n-3$ & 9-HOTrE & $9.87 \pm 1.13$ & $7.42 \pm 1.24$ & $7.42 \pm 1.46$ & $7.41 \pm 1.56$ \\
\hline & $18: 3 n-3$ & 9-OxoOTrE & $6.03 \pm 0.63$ & $5.03 \pm 0.70$ & $4.32 \pm 0.53$ & $4.78 \pm 0.76$ \\
\hline & $20: 4 n-6$ & 5-HETE & $22.06 \pm 2.07$ & $28.62 \pm 3.66$ & $46.41 \pm 10.80$ & $45.89 \pm 10.89$ \\
\hline & $20: 4 n-6$ & 5-oxoETE & $4.91 \pm 0.61$ & $9.34 \pm 1.34$ & $9.88 \pm 1.91$ & $15.54 \pm 3.36$ \\
\hline & $20: 5 n-3$ & 5-HEPE & $2.03 \pm 0.60$ & $2.82 \pm 0.43$ & $3.96 \pm 1.24$ & $2.52 \pm 0.81$ \\
\hline & $20: 3 n-9$ & 5-HETrE & $0.54 \pm 0.04$ & $0.56 \pm 0.08$ & $0.78 \pm 0.23$ & $0.63 \pm 0.14$ \\
\hline & $22: 6 n-3$ & 7-HDoHE & $1.00 \pm 0.29$ & $0.78 \pm 0.29$ & $0.90 \pm 0.33$ & $1.70 \pm 0.74$ \\
\hline & $20: 4 n-6$ & LTB4 & ND & ND & ND & ND \\
\hline & $20: 4 n-6$ & 12-OxoLTB4 & ND & ND & ND & ND \\
\hline & $20: 5 n-3$ & LTB5 & ND & ND & ND & ND \\
\hline & \multicolumn{2}{|r|}{ 5-LOX sum } & $47.32 \pm 4.37$ & $56.14 \pm 6.69$ & $74.73 \pm 13.28$ & $82.66 \pm 18.27$ \\
\hline \multirow{3}{*}{$\begin{array}{l}\times \\
0 \\
01 \\
01\end{array}$} & $20: 4 n-6$ & 8-HETE & $7.87 \pm 1.22$ & $11.96 \pm 1.67$ & $12.97 \pm 2.56$ & $25.10 \pm 8.83$ \\
\hline & $20: 5 n-3$ & 8-HEPE & ND & ND & ND & $1.26 \pm 0.63$ \\
\hline & \multicolumn{2}{|r|}{ 8-LOX sum } & $8.37 \pm 1.36$ & $12.29 \pm 1.73$ & $13.58 \pm 2.86$ & $26.36 \pm 9.45$ \\
\hline \multirow{12}{*}{$\begin{array}{l}\stackrel{x}{0} \\
\stackrel{1}{\sim} \\
\stackrel{0}{n}\end{array}$} & $18: 2 n-6$ & 9-HODE & $159.30 \pm 15.66$ & $161.34 \pm 24.60$ & $152.36 \pm 25.73$ & $160.55 \pm 36.15$ \\
\hline & $18: 2 n-6$ & 9-OxoODE & $197.34 \pm 21.13$ & $183.58 \pm 29.05$ & $159.24 \pm 27.47$ & $154.68 \pm 36.75$ \\
\hline & $20: 2 n-6$ & 11-HEDE & $1.22 \pm 0.39$ & $2.11 \pm 0.70$ & $0.99 \pm 0.58$ & $2.45 \pm 0.93$ \\
\hline & $20: 3 n-6$ & 8-HETrE & $0.73 \pm 0.17$ & $1.39 \pm 0.44$ & $1.65 \pm 0.41$ & $1.43 \pm 0.46$ \\
\hline & $20: 4 n-6$ & 12-HETE & $276.39 \pm 89.23$ & $275.19 \pm 81.62$ & $259.14 \pm 50.35$ & $450.78 \pm 174.70$ \\
\hline & $20: 4 n-6$ & tetranor 12-HETE & $1.17 \pm 0.32$ & $3.13 \pm 1.48$ & $1.20 \pm 0.55$ & $2.46 \pm 1.03$ \\
\hline & $20: 4 n-6$ & 12-OxoETE & $2.02 \pm 0.53$ & $2.18 \pm 0.62$ & $1.94 \pm 0.50$ & $2.43 \pm 0.58$ \\
\hline & $20: 4 n-6$ & 5(S),12(S)-DiHETE & $19.76 \pm 4.36$ & $14.11 \pm 4.74$ & $16.99 \pm 4.51$ & $35.78 \pm 14.36$ \\
\hline & $20: 5 n-3$ & 12-HEPE & $23.26 \pm 5.29$ & $20.90 \pm 5.70$ & $17.70 \pm 4.17$ & $36.74 \pm 14.25$ \\
\hline & $22: 6 n-3$ & 14-HDoHE & $14.66 \pm 3.15$ & $23.13 \pm 7.66$ & $14.55 \pm 3.55$ & $20.09 \pm 6.90$ \\
\hline & \multirow{2}{*}{\multicolumn{2}{|c|}{$\begin{array}{c}\text { 12-LOX sum } \\
\text { 12-LOX sum (no HODEs) }\end{array}$}} & $695.85 \pm 124.33$ & $687.04 \pm 131.90$ & $625.77 \pm 88.72$ & $867.39 \pm 254.05$ \\
\hline & & & $339.21 \pm 99.63$ & $342.13 \pm 98.72$ & $314.17 \pm 59.88$ & $552.16 \pm 211.45$ \\
\hline \multirow{14}{*}{$\begin{array}{l}\times \\
0 \\
1 \\
\stackrel{0}{\circ}\end{array}$} & $18: 2 n-6$ & 13-HODE & $1162.42 \pm 129.19$ & $1115.86 \pm 158.22$ & $1085.17 \pm 166.57$ & $1069.09 \pm 235.19$ \\
\hline & $18: 2 n-6$ & 13-OxOODE & $536.39 \pm 57.11$ & $502.95 \pm 74.24$ & $433.76 \pm 90.12$ & $392.12 \pm 111.52$ \\
\hline & $18: 3 n-3$ & 13-HOTrE & $16.50 \pm 1.73$ & $17.41 \pm 4.28$ & $13.12 \pm 2.91$ & $13.39 \pm 3.41$ \\
\hline & $18: 3 n-6$ & 13-HOTrE(g) & ND & ND & ND & ND \\
\hline & $20: 2 n-6$ & 15-HEDE & ND & $0.78 \pm 0.33$ & $0.73 \pm 0.21$ & $0.55 \pm 0.19$ \\
\hline & $20: 2 n-6$ & 15-OxoEDE & ND & $0.63 \pm 0.19$ & $0.21 \pm 0.08$ & $0.51 \pm 0.19$ \\
\hline & $20: 4 n-6$ & 15-HETE & $45.15 \pm 3.69$ & $80.38 \pm 10.75$ & $99.97 \pm 8.32$ & $115.59 \pm 15.76$ \\
\hline & $20: 4 n-6$ & 15-OxoETE & $4.03 \pm 0.73$ & $3.64 \pm 0.61$ & $3.59 \pm 0.60$ & $4.84 \pm 0.89$ \\
\hline & $20: 4 n-6$ & 8(S),15(S)-DiHETE & ND & ND & $2.74 \pm 0.65$ & $2.37 \pm 0.83$ \\
\hline & $20: 4 n-6$ & 5(S),15(S)-DiHETE & ND & ND & ND & ND \\
\hline & $20: 5 n-3$ & 15-HEPE & $1.89 \pm 0.63$ & $5.95 \pm 2.04$ & $4.31 \pm 1.15$ & $3.03 \pm 1.14$ \\
\hline & $22: 6 n-3$ & 17-HDoHE & $3.85 \pm 0.71$ & $9.20 \pm 3.18$ & $3.75 \pm 1.54$ & $4.16 \pm 1.19$ \\
\hline & \multirow{2}{*}{\multicolumn{2}{|c|}{$\begin{array}{c}\text { 15-LOX sum } \\
\text { 15-LOX sum (no HODEs) }\end{array}$}} & $1771.42 \pm 189.33$ & $1737.31 \pm 247.38$ & $1648.35 \pm 259.93$ & $1606.02 \pm 347.86$ \\
\hline & & & $72.60 \pm 5.86$ & $118.49 \pm 19.44$ & $129.43 \pm 11.17$ & $144.80 \pm 19.51$ \\
\hline \multirow{2}{*}{\multicolumn{3}{|c|}{$\begin{array}{c}\text { Total LOX sum } \\
\text { Total LOX sum (no HODEs) }\end{array}$}} & $2522.97 \pm 304.77$ & $2492.78 \pm 361.52$ & $2362.43 \pm 328.21$ & $2582.43 \pm 556.64$ \\
\hline & & & $467.51 \pm 108.61$ & $529.04 \pm 115.08$ & $531.91 \pm 74.87$ & $805.99 \pm 556.64$ \\
\hline
\end{tabular}

Values are mean \pm SEM of 8-12 tendons from 4-6 rats/group. ND = Below limits of detection of the assay. 
bioRxiv preprint doi: https://doi.org/10.1101/2021.01.08.425901; this version posted January 9, 2021. The copyright holder for this preprint (which was not certified by peer review) is the author/funder, who has granted bioRxiv a license to display the preprint in perpetuity. It is made available under aCC-BY 4.0 International license.

Supplemental Table 1C: Epoxygenase (CYP) metabolite concentration (pmol/g) in overloaded rat plantaris tendons

\begin{tabular}{|c|c|c|c|c|c|c|}
\hline Pathway & Substrate & Analyte & Control & Day 3 overload & Day 7 overload & Day 28 overload \\
\hline \multirow{25}{*}{ 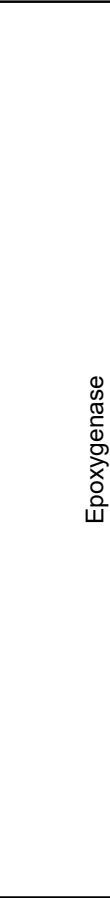 } & $18: 2 n-6$ & 9(10)-ЕрOME & $798.19 \pm 83.46$ & $741.95 \pm 104.39$ & $582.41 \pm 127.71$ & $556.66 \pm 100.94$ \\
\hline & $18: 2 n-6$ & 12(13)-ЕрОМЕ & $687.79 \pm 47.87$ & $626.89 \pm 96.92$ & $504.20 \pm 128.12$ & $403.66 \pm 62.71$ \\
\hline & $18: 2 n-6$ & 9,10-DiHOME & $79.79 \pm 7.61$ & $68.93 \pm 10.53$ & $63.22 \pm 10.77$ & $72.02 \pm 17.17$ \\
\hline & $18: 2 n-6$ & 12,13-DiHOME & $78.48 \pm 6.25$ & $69.60 \pm 10.00$ & $62.11 \pm 10.56$ & $65.98 \pm 11.81$ \\
\hline & $20: 4 n-6$ & 5(6)-EpETrE & $6.63 \pm 0.78$ & $10.63 \pm 1.22$ & $10.40 \pm 1.60$ & $14.85 \pm 3.70$ \\
\hline & $20: 4 n-6$ & 8(9)-EpETrE & ND & ND & ND & ND \\
\hline & $20: 4 n-6$ & 11(12)-EpETrE & $32.29 \pm 5.63$ & $45.00 \pm 5.81$ & $40.09 \pm 10.00$ & $87.48 \pm 27.67$ \\
\hline & $20: 4 n-6$ & 14(15)-EpETrE & $16.01 \pm 2.44$ & $21.46 \pm 4.29$ & $18.72 \pm 5.57$ & $43.75 \pm 12.39$ \\
\hline & $20: 4 n-6$ & 5,6-DiHETrE & ND & $0.65 \pm 0.31$ & $0.93 \pm 0.39$ & $1.56 \pm 0.62$ \\
\hline & $20: 4 n-6$ & 8,9-DiHETrE & ND & $0.55 \pm 0.18$ & ND & $1.04 \pm 0.33$ \\
\hline & $20: 4 n-6$ & 11,12-DiHETrE & $2.69 \pm 0.89$ & $2.48 \pm 0.90$ & $6.33 \pm 0.44$ & $8.59 \pm 2.35$ \\
\hline & $20: 4 n-6$ & 14,15-DiHETrE & $4.65 \pm 0.61$ & $6.31 \pm 0.79$ & $8.20 \pm 1.31$ & $13.42 \pm 2.82$ \\
\hline & $20: 4 n-6$ & 20-HETE & $18.31 \pm 3.93$ & $22.98 \pm 5.38$ & $17.45 \pm 5.38$ & $41.42 \pm 12.50$ \\
\hline & $20: 5 n-3$ & 8(9)-EpETE & ND & ND & ND & ND \\
\hline & $20: 5 n-3$ & 11(12)-EpETE & ND & ND & ND & ND \\
\hline & $20: 5 n-3$ & 14(15)-ЕpETE & ND & $3.67 \pm 1.17$ & ND & $6.53 \pm 2.04$ \\
\hline & $20: 5 n-3$ & 17(18)-ЕpETE & $1.19 \pm 0.41$ & $1.36 \pm 0.48$ & $1.27 \pm 0.62$ & $2.68 \pm 0.86$ \\
\hline & $20: 5 n-3$ & 18-HEPE & $1.82 \pm 0.99$ & $3.52 \pm 0.70$ & $3.43 \pm 0.89$ & $4.39 \pm 1.25$ \\
\hline & $22: 6 n-3$ & 7(8)-EpDPE & $1.38 \pm 0.38$ & $1.73 \pm 0.37$ & $0.76 \pm 0.36$ & $1.84 \pm 0.85$ \\
\hline & $22: 6 n-3$ & 10(11)-EpDPE & $8.06 \pm 2.19$ & $8.16 \pm 1.79$ & $5.21 \pm 1.34$ & $10.60 \pm 3.72$ \\
\hline & $22: 6 n-3$ & 13(14)-EpDPE & $4.26 \pm 1.13$ & $5.45 \pm 0.95$ & $3.03 \pm 0.74$ & $5.40 \pm 1.72$ \\
\hline & $22: 6 n-3$ & 16(17)-EpDPE & $2.78 \pm 0.65$ & $4.29 \pm 0.63$ & $2.30 \pm 0.69$ & $3.88 \pm 1.14$ \\
\hline & $22: 6 n-3$ & 19(20)-EpDPE & ND & $2.45 \pm 1.20$ & ND & ND \\
\hline & & Sum & $1746.31 \pm 151.70$ & $1648.37 \pm 230.92$ & $1333.37 \pm 275.62$ & $1349.65 \pm 218.82$ \\
\hline & & Sum (no EpOMEs) & $102.06 \pm 18.55$ & $141.00 \pm 22.10$ & $121.44 \quad \pm 24.74$ & $251.33 \pm 74.69$ \\
\hline
\end{tabular}

Values are mean \pm SEM of 8-12 tendons from 4-6 rats/group. ND = Below limits of detection of the assay. 
bioRxiv preprint doi: https://doi.org/10.1101/2021.01.08.425901; this version posted January 9, 2021. The copyright holder for this preprint (which was not certified by peer review) is the author/funder, who has granted bioRxiv a license to display the preprint in perpetuity. It is made available under aCC-BY 4.0 International license.

Supplemental Table 1D: Specialized pro-resolving mediator concentration $(\mathrm{pmol} / \mathrm{g})$ in overloaded rat plantaris tendons

\begin{tabular}{|c|c|c|c|c|c|c|}
\hline Pathway & Substrate & Analyte & Control & Day 3 overload & Day 7 overload & Day 28 overload \\
\hline \multirow{24}{*}{ 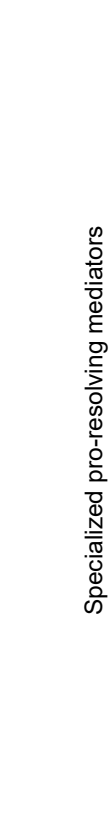 } & $20: 4 n-6$ & LXA4 & ND & $\overline{N D}$ & ND & ND \\
\hline & $20: 4 n-6$ & LXB4 & ND & ND & ND & ND \\
\hline & $20: 4 n-6$ & LXA5 & ND & ND & ND & ND \\
\hline & $20: 4 n-6$ & 15-epi LXA4 & ND & ND & ND & ND \\
\hline & $20: 4 n-6$ & 15-oxo LXA4 & ND & ND & ND & ND \\
\hline & $22: 5 n-3$ & RvE1 & $\overline{N D}$ & ND & ND & ND \\
\hline & $22: 5 n-3$ & RvE3 & ND & ND & ND & ND \\
\hline & $22: 6 n-3$ & RvD5(n-3DPA) & ND & ND & ND & ND \\
\hline & $22: 6 n-3$ & RvD1 \& AT-RvD1 & $32.74 \pm 3.98$ & $37.77 \pm 9.02$ & $43.94 \pm 11.10$ & $38.18 \pm 13.79$ \\
\hline & $22: 6 n-3$ & $\mathrm{RvD2}$ & ND & $21.04 \pm 10.83$ & $45.43 \pm 15.68$ & $37.73 \pm 18.33$ \\
\hline & $22: 6 n-3$ & RvD3 & ND & ND & ND & ND \\
\hline & $22: 6 n-3$ & AT-RvD3 & ND & ND & ND & ND \\
\hline & $22: 6 n-3$ & RvD4 & ND & ND & ND & ND \\
\hline & $22: 6 n-3$ & RvD5 & ND & ND & ND & ND \\
\hline & $22: 6 n-3$ & RvD6 & ND & ND & ND & $2.92 \pm 0.96$ \\
\hline & $22: 6 n-3$ & 8-oxoRvD1 & ND & ND & ND & ND \\
\hline & $22: 6 n-3$ & 17-oxoRvD1 & ND & ND & ND & ND \\
\hline & $22: 6 n-3$ & PD1 & ND & ND & $2.58 \pm 1.41$ & $2.41 \pm 1.31$ \\
\hline & $22: 6 n-3$ & AT-PD1 & ND & ND & ND & ND \\
\hline & $22: 6 n-3$ & 10S,17S-DiHDoHE & ND & ND & ND & ND \\
\hline & $22: 6 n-3$ & 22-OH-PD1 & ND & ND & ND & ND \\
\hline & $22: 6 n-3$ & Maresin1 & ND & ND & ND & ND \\
\hline & $22: 6 n-3$ & 7(S)-Maresin1 & ND & ND & ND & ND \\
\hline & & Sum & $34.69 \pm 3.98$ & $60.67 \pm 11.76$ & $93.72 \pm 24.92$ & $82.92 \pm 31.06$ \\
\hline
\end{tabular}

Values are mean \pm SEM of 8-12 tendons from 4-6 rats/group. ND = Below limits of detection of the assay. 
bioRxiv preprint doi: https://doi.org/10.1101/2021.01.08.425901; this version posted January 9, 2021. The copyright holder for this preprint (which was not certified by peer review) is the author/funder, who has granted bioRxiv a license to display the preprint in perpetuity. It is made available under aCC-BY 4.0 International license.

Supplemental Table 1E: Non-enzymatic metabolite concentration $(\mathrm{pmol} / \mathrm{g})$ in overloaded rat plantaris tendons

\begin{tabular}{|c|c|c|c|c|c|c|}
\hline Pathway & Substrate & Analyte & Control & Day 3 overload & Day 7 overload & Day 28 overload \\
\hline \multirow{9}{*}{ 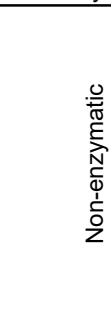 } & $20: 4 n-6$ & 9-HETE & $3.15 \pm 0.64$ & $3.63 \pm 1.30$ & $6.07 \pm 1.10$ & $9.62 \pm 3.02$ \\
\hline & $20: 5 n-3$ & 9-HEPE & ND & ND & ND & ND \\
\hline & $22: 6 n-3$ & 8-HDoHE & $2.42 \pm 0.60$ & $3.42 \pm 0.65$ & $2.24 \pm 0.63$ & $3.64 \pm 1.18$ \\
\hline & $22: 6 n-3$ & 10-HDoHE & $3.29 \pm 0.66$ & $4.93 \pm 0.71$ & $3.36 \pm 0.72$ & $5.60 \pm 1.82$ \\
\hline & $22: 6 n-3$ & 11-HDoHE & $2.71 \pm 0.75$ & $3.51 \pm 0.85$ & $1.92 \pm 0.73$ & $3.83 \pm 1.18$ \\
\hline & $22: 6 n-3$ & 13-HDoHE & $9.09 \pm 1.13$ & $12.46 \pm 1.64$ & $11.43 \pm 1.42$ & $13.82 \pm 2.10$ \\
\hline & $22: 6 n-3$ & 16-HDoHE & $7.40 \pm 1.24$ & $9.17 \pm 1.30$ & $8.35 \pm 1.61$ & $11.23 \pm 2.75$ \\
\hline & $22: 6 n-3$ & 20-HDoHE & ND & ND & $3.53 \pm 1.39$ & $4.43 \pm 2.17$ \\
\hline & & $\mathrm{um}$ & $30.06 \pm 4.86$ & $40.48 \pm 6.73$ & $36.99 \pm 6.88$ & $53.31 \pm 14.53$ \\
\hline
\end{tabular}

Values are mean \pm SEM of 8-12 tendons from 4-6 rats/group. ND = Below limits of detection of the assay. 